Fertility, Mobility, and Educational Reproduction:

\title{
A New Method to Estimate Prospective Models Using Retrospective Data
}

\author{
Skopek, J.* \& Leopold, T.**
}

\section{Discussion Paper}

March 2018

\footnotetext{
* Trinity College Dublin, Department of Sociology, Ireland (skopekj@tcd.ie)

** University of Amsterdam, Department of Sociology, The Netherlands
}

\section{Abstract}

Prospective models of intergenerational reproduction consider not only the social reproduction of attributes such as education, but also the demographic reproduction of individuals who carry these attributes. This study introduces a method that substantially reduces the data requirements of prospective models. The method allows estimating prospective models based on retrospective data commonly available in surveys. It addresses two key issues retrospective sampling bias, and the problem of identifying representative cohorts. Additionally, we introduce a decomposition technique disentangling social and demographic pathways of reproduction. We illustrate the method using German data from NEPS and SOEP, focusing on educational reproduction of German men and women born between 1930 and 1945 . The analysis offers new estimates of the expected number of higher and lower educated children born to men and women of different levels of education. Findings show that reproduction is constrained by educational gradients in women's fertility, particularly in West Germany. We conclude that prospective designs advance our understanding of social inequality and its reproduction in families. The method that we introduce will facilitate future prospective research on social stratification.

Key words:

educational reproduction; social mobility; fertility; prospective models; East and West Germany 


\section{Introduction}

Most studies on intergenerational reproduction have focused on the association between social origin and status attainment (Blossfeld et al. 2016; Breen 2004; Breen, Luijkx, Müller, et al. 2009; Breen and Jonsson 2005; Erikson and Goldthorpe 1993; Goldthorpe 1996; Haller 1990; Jackson 2013; Shavit and Blossfeld 1993). These studies are based on a retrospective approach. Looking backwards from anchor persons to their parents, this approach examines how parents transmit their social position to children or, conversely, how children inherit their social position from parents.

An important limitation of the retrospective approach is that it conditions on fertility: It takes two family generations in order to transmit, or to inherit, social positions. Yet, an analysis that is conditioned on the existence of a second generation ignores the process by which this second generation came into existence. In other words, the analysis of intergenerational reproduction is limited to the social reproduction of individual attributes, ignoring the demographic reproduction of individuals who carry these attributes. As a result, the retrospective approach treats social origin as an exogenous factor rather than as a phenomenon explained by processes of intergenerational reproduction.

In contrast, the prospective approach to intergenerational reproduction considers not only the social reproduction of attributes such as social position, but also the demographic reproduction of individuals carrying these attributes (Lawrence and Breen 2016; Mare and Maralani 2006). By embedding stratification mechanisms into a demographic framework, prospective studies can tackle a whole set of new descriptive and analytical research questions. Yet, prospective studies on intergenerational reproduction are still rare in stratification research. Recent work has examined educational reproduction of Indonesian women (Mare and Maralani 2006), South Korean women (Kye and Mare 2012), black and white U.S. women (Maralani 2013; Mare 1997), high school graduates from Wisconsin (Lawrence and Breen 2016), and, 
most recently, men and women in the UK (Breen and Ermisch 2017). For many European countries that differ from these contexts both demographically and in terms of social inequality in educational opportunity, almost no prospective studies exist.

A major reason for this gap of knowledge are the high data requirements of the prospective approach. In contrast to the retrospective approach anchored at a current generation and looking backwards to their parents, a prospective approach follows up a cohort and its offspring. An important implication is that intergenerational reproduction from a prospective point of view can be studied only for older cohorts who have completed their fertility. Previous prospective studies have used long-running panel data that covered individuals (with and without children) as well as all of their children and followed the child generation over decades until their process of status attainment was complete.

Building on recent methodological advances, the present study proposes a new method that uses retrospective data to gain novel prospective insight into processes of intergenerational reproduction. By the term retrospective data we refer to data that are typically used in social mobility research, including representative samples of respondents, data on their status attainment, and data on their parents' socio-economic status. Focusing on educational reproduction, we introduce a method that allows exploiting these data for prospective research designs of intergenerational reproduction. We address and provide solutions to two key problems of retrospective data: retrospective sampling bias and the identification of representative cohorts of potential parents. In addition, we propose a method that disentangles demographic and social pathways in processes of intergenerational reproduction.

We illustrate our method using retrospective data from the German National Educational Panel Study (NEPS) and the German Socio-Economic Panel Study (SOEP). Starting from these respondents, we reconstruct the educational reproduction of men and women born in Germany between 1930 and 1945. Germany provides an interesting context for studying mechanisms of educational reproduction, as contrasts between the former German Democratic Republic 
(GDR) and the Federal Republic of Germany (FRG) particularly in terms of education systems and family policy have differentially shaped processes of fertility and social mobility in both parts of the country.

\section{Retrospective and prospective accounts of intergenerational reproduction}

The retrospective approach of intergenerational reproduction focuses on the association between social origin (such as parental class or education) and occupational or educational attainment. Conventional mobility research based on this approach is offspring-centered because it takes a population of individuals - generation $2(G 2)$ - and asks "where do they come from?" by looking backwards to their parents - generation 1 (G1) (Hillmert 2013). Retrospective data are survey data on respondents and their parents on which the large majority of mobility studies are based. Offspring is the unit of analysis and parents (mostly only one parent) are treated as variables.

This approach refers to a parent generation $G 1$ only from a retrospective vantage point. Yet, G1 did not emerge from a clearly defined population prior in time (Blau and Duncan 1967). For example, although the population of individuals born in 1970 is identifiable as an offspring generation $G 2$ and as a birth cohort, their parents $G 1$ represent a selective subset of birth cohorts $C 1$, which includes childless people as well as parents who varied in their timing of childbearing and number of children. There is no obvious way of identifying a cohort $C l$ of (potential) parents.

Parents $G 1$ of offspring generation $G 2$ belong to birth cohorts that include childless individuals who have zero probability of inclusion (even as a variable) in a retrospective study that selects $G 2$ as anchor persons. In addition, higher-parity parents $G 1$ are over-represented in samples drawn from their offspring $G 2$, and parents $G 1$ whose children died early are underrepresented. These problems are known as retrospective bias in conventional studies of intergenerational reproduction (Song and Mare 2015). In standard retrospective data, the 
distribution of parental SES is representative of the offspring's conditions of socialization, but it is not representative of the distribution of SES in any previous population. Nonetheless, as Lawrence and Breen (2016) have recently noted, retrospective social mobility studies often interpret their findings as if parent data represented previous generations. Retrospective accounts of intergenerational reproduction are biased to the extent that processes of demographic reproduction depend on SES in $C 1$ and, accordingly, social origin in $G 2$.

In a prospective approach, the direction of inference is reversed. It starts from individuals in birth cohort $C l$ as a unit of analysis and uses variables to describe their fertility behavior and their children's attributes. A prospective approach considers not only those who become parents but also those who remain childless. Reproduction from a prospective perspective involves not only social reproduction, i.e., the extent to which social positions are passed on to children, but also demographic reproduction, i.e., whether and how many children are born to an individual.

Retrospective and the prospective approaches reflect different ideas about how to conceptualize and measure intergenerational reproduction, and each approach generalizes to different populations. A defining feature of the prospective approach is that it examines unconditional chances instead of conditional chances of reproduction. As an illustration, consider the following example. A retrospective study finds that children of college-educated mothers have twice the chances of obtaining a college degree compared to children of highschool educated mothers. A prospective study finds that college-educated and high-school educated women are equally likely to have a college-educated child. These findings seem contradictory at first glance, but they can be reconciled if college-educated women more often remain childless. In this example, the demographic pathway of intergenerational reproduction fully offsets the effects of the social pathway of intergenerational reproduction.

By treating social origin as an exogenous variable, traditional stratification research eclipses demographic pathways of intergenerational reproduction. In studies of inequality, this neglect results in an incomplete understanding of changes, particularly if demographic and 
social pathways of reproduction are interrelated. A prospective approach is integrative not only because it considers both pathways, but also because it combines mechanisms that have been previously studied in separate fields, namely demographic life course research and social mobility research.

A further important difference between retrospective and prospective approaches is the population targeted for inference and generalization. Prospective studies can be representative of a cohort of individuals, some of which reproduce and some of which do not. Yet, inference does not extend to any birth cohort of these individuals' children, because a birth cohort can produce children who belong to a wide range of subsequent birth cohorts. For example, assuming reproductive ages between 15 and 49, individuals born in 1950 can produce offspring born between 1965 and 2000 .

Due to different concepts and populations, retrospective and prospective approaches require different kinds of data. Retrospective studies place few demands on the data and can be conducted on the basis of widely available cross-sectional data (Breen 2004, 2010; Breen, Luijkx, Muller, et al. 2009; Erikson and Goldthorpe 1993). A prospective approach, in contrast, requires a long window of observation in order to capture attainment processes of a cohort of individuals and - ideally - their entire offspring (Lawrence and Breen 2016; Song and Mare 2015). These demands are met only by long-running genealogical panel surveys or life-history data including full child biographies. Given that the latter are collected retrospectively from samples of older people, survivor bias might occur if mortality is associated with the processes under study.

Considering these data requirements, it is not surprising that prospective studies on intergenerational reproduction and mobility are still rare in stratification research. Recent prospective work has examined educational reproduction of Indonesian women (Mare and Maralani 2006), South Korean women (Kye and Mare 2012), black and white U.S. women (Mare, 1997; Maralani, 2013), and males and females graduating from Wisconsin high schools 
in 1957 (Lawrence and Breen 2016). For European countries that differ from these contexts demographically and in terms of social inequality in educational opportunity, almost no studies exist. Notable exceptions are a recent study on men and women in the UK (Breen and Ermisch 2017) and two studies of the impact of differential fertility of West German women on changes in educational inequality. Instead of employing prospective panel data, the latter two studies used simulations based on pooled retrospective datasets and census data (Buis, Mönkediek, and Hillmert 2012; Hillmert 2013).

Although prospective designs may advance our knowledge about intergenerational reproduction, the scarcity of suitable data remains an important practical obstacle. Yet, this obstacle would be removed if methods were available to conduct prospective analyses even in the absence of truly prospective data. One possibility is to use surveys of older populations (e.g., SHARE or HRS) that are retrospective in nature but may mimic long-running panel data through biographic life-course data on respondents and their offspring (Breen, Ermisch, and Helske 2017). However, measurement error resulting from recall problems and survivor bias may undermine confidence in prospective findings obtained from these data. Moreover, these surveys are often limited by restrictions on the collection of child data. For example, in the SHARE detailed information is collected only for up to four children and data about children's social position are limited.

In this article, we propose an alternative solution that exploits standard retrospective mobility data for prospective research designs. A major advantage of this approach is that it works with data that are widely available for many countries at various points in time. The method we propose is also useful for supplementing conventional mobility studies by a prospective perspective. In the following, we first describe a simple model of educational reproduction. Then we explain how retrospective data can be used in prospective designs of intergenerational educational reproduction. 


\section{A simple model of educational reproduction}

To illustrate our method, we use a simple model of educational reproduction. By "simple" we mean that the model considers fertility as the only demographic pathway of educational reproduction. A more elaborate model could include mechanisms such as educational assortative mating. Our model shares basic features with previous work relying on population renewal models (Mare and Maralani 2006; Song and Mare 2015) which estimate the number of children in different educational levels that individuals of different educational levels are expected to produce. An important feature of educationally stratified renewal rates is that they link educational distributions across generations.

In our model, fertility enters the model in two steps - parenthood and, conditional on parenthood, the number of children. Our model specifies population-level and family-level effects, which may work in opposite directions (Maralani 2013). For instance, a higher number of children born to an individual may increase the probability that at least one child will attain higher education. However, a higher number of siblings, i.e., a larger family size, may reduce a child's educational opportunities as a result of resource dilution within the family (Becker and Tomes 1976; Downey 1995; Featherman and Hauser 1978) or birth order effects (Black, Devereux, and Salvanes 2005; Conley and Glauber 2006).

We formulate our model using a notation similar to Song and Mare (2015). The number of offspring attaining educational level $j$ that a person of educational level $i$ born in cohort $C$ is expected to produce is defined as a conditional rate of educational reproduction:

$$
r_{j i \mid f, f>0}=f \cdot P_{j i \mid f}
$$

where $f$ is the number of children of a parent of educational level $i$ and $P_{j i \mid f}$ is the probability that a parent's child attains educational level $j$ given the parent's educational level $i$ and family size. The overall effect of family size depends on the number of children in the 
family and its marginal effect on educational opportunity $\left(\frac{\partial r}{\partial f}=P_{j i \mid f}+f \cdot P_{j i \mid f}\right)$. The average rate of producing children of educational level $j$ in the population of parents with education $i$ can be determined via integration over the family size of parents with educational level $i$

$$
r_{j i \mid f>0}=\int r_{j i \mid f, f>0} d f
$$

In the following step, we consider childless individuals to calculate the unconditional educational reproduction rate for a representative cohort:

$$
r_{j i}=P(f=0 \mid i) \cdot 0+[1-P(f=0 \mid i)] \cdot r_{j i \mid f>0}
$$

where $P(f=0 \mid i)$ is the probability of a person of educational level $i$ to remain childless. The unconditional rate $r_{j i}$ represents the number of children of educational level $j$ that a randomly selected person of educational level $i$ is expected to produce. Consequently, we can write the joint demographic and mobility effect (Song and Mare 2015) comparing persons of educational level $i$ to persons with educational level $i^{\prime}$ in producing offspring with educational level $j$ as:

$$
\Delta^{j}=r_{j i}-r_{j i}
$$

To illustrate our method, we will estimate equation (4) for men and women in East and West Germany. ${ }^{1}$

\section{Fertility and mobility in processes of intergenerational reproduction}

Our prospective model allows assessing the relative importance of fertility (demographic pathway) and mobility (social pathway) in educational reproduction. To decompose these effects, we calculate counterfactual reproduction rates by exchanging fertility patterns of persons in educational level $i$ and persons in educational level $i^{\prime}$. Consider two educational 
groups - higher educated persons $(\mathrm{H})$ and lower educated persons $(\mathrm{L})$ - producing higher educated children $(h)$ and lower educated children $(l)$. For outcome $h$, we can calculate factual and counterfactual rates of reproduction:

\begin{tabular}{cccc}
\hline & & \multicolumn{2}{c}{ Fertility } \\
& & $\mathrm{L}$ & $\mathrm{H}$ \\
\cline { 3 - 4 } Mobility & $\mathrm{L}$ & $h_{L L}$ & $h_{L H}$ \\
& $\mathrm{H}$ & $h_{H L}$ & $h_{H H}$ \\
\hline
\end{tabular}

$h_{L L}$ and $h_{H H}$ are the rates of producing offspring in a certain educational category based on fertility and mobility behavior as observed in the data. For example, $h_{L L}$ for West German women born between 1930 and 1945 gives the average number of children attaining higher education that a woman with educational level $L$ is expected to produce; $h_{L H}$ is the expected number of higher educated children if women with education $L$ had the fertility patterns of women with education $H$. Because $h_{L H}$ and $h_{H L}$ are hypothetical we call them counterfactual rates of educational reproduction. ${ }^{2}$

Based on the above rates, we calculate the joint fertility and mobility effect as the difference between $H$ and $L$ in producing $h$ children,

$$
\Delta^{h}=h_{H H}-h_{L L}
$$

measuring the absolute difference between $H$ and $L$ women in the expected number of higher educated children.

How much of this difference is attributable to differential fertility and how much is due to mobility (i.e., inequality of educational opportunity)? An additive decomposition of the joint effect would allow us to answer this question. Therefore, we write the joint effect as a linear combination of a fertility and a mobility component:

$$
\Delta^{h}=\Delta_{f}^{h}+\Delta_{m}^{h}
$$


If $\Delta^{h}$ is known, we need to estimate only one of the two components. To calculate $\Delta_{f}^{h}$, we consider two questions. First, what would be the joint effect if $H$ had the fertility of $L$ ? Based on the counterfactual rate

$$
\Delta^{\prime h}=h_{H L}-h_{L L}
$$

we can write the difference between observed and counterfactual rates as

$$
\Delta^{h}-\Delta^{\prime h}=\left(h_{H H}-h_{L L}\right)-\left(h_{H L}-h_{L L}\right)=h_{H H}-h_{H L}
$$

Second, what would be the joint effect if $L$ had the fertility of $H$ ? Based on the second counterfactual rate

$$
\Delta^{\prime \prime h}=h_{H H}-h_{L H}
$$

we can write the difference between observed and counterfactual rates as

$$
\Delta^{h}-\Delta^{\prime \prime}{ }^{h}=\left(h_{H H}-h_{L L}\right)-\left(h_{H H}-h_{L H}\right)=h_{L H}-h_{L L}
$$

(8) and (10) represent different viewpoints that are likely to differ numerically. Therefore, decomposition results can differ depending on an arbitrary decision on the reference category. To avoid this issue, we can take the average of (8) and (10) for calculating the fertility component:

$$
\Delta_{f}^{h}=\frac{1}{2}\left(h_{L H}-h_{L L}+h_{H H}-h_{H L}\right)
$$

Based on equation (6) we can now calculate the mobility component $\Delta_{m}^{h}$ of the joint effect. ${ }^{3}$ In general, the fertility component (11) is zero if $H$ and $L$ do not differ in their fertility.

If the average number of children of $L$ and $H$ are known (cohort fertility rates $F_{L}$ and $F_{H}$ ), the calculation of the production rate of lower educated children $(l)$ is straightforward, given that 


$$
\begin{gathered}
F_{L}=l_{L L}+h_{L L}=l_{H L}+h_{H L} \\
\text { and } \\
F_{H}=l_{H H}+h_{H H}=l_{L H}+h_{L H}
\end{gathered}
$$

\begin{tabular}{|c|c|c|c|}
\hline & & \multicolumn{2}{|c|}{ Fertility } \\
\hline & & $\mathrm{L}$ & $\mathrm{H}$ \\
\hline \multirow{2}{*}{ Mobility } & $\mathrm{L}$ & $l_{L L}=F_{L}-h_{L L}$ & $l_{L H}=F_{H}-h_{L H}$ \\
\hline & $\mathrm{H}$ & $l_{H L}=F_{L}-h_{H L}$ & $l_{H H}=F_{H}-h_{H H}$ \\
\hline
\end{tabular}

The rates of producing lower educated children are

After calculating rates for outcome $h$, all related quantities for outcome $l$ can be derived analytically. Note that the joint effects for outcomes $h$ and $l$ are not necessarily of the same direction and magnitude. The absolute value of the mobility component, however, is identical for all outcomes while signs are reversed: ${ }^{4}$

$$
\Delta_{m}^{h}=-\Delta_{m}^{l}
$$

The absolute value of the fertility components can differ by outcome. The fertility components for different outcomes, however, add up to the difference in total fertility between $H$ and $L:^{5}$

$$
F_{H}-F_{L}=\Delta_{f}^{h}+\Delta_{f}^{l}
$$

\section{Linking educational distributions of a population to its offspring}

Population renewal models allow us to link educational distributions (Kye and Mare 2012; Mare and Maralani 2006; Song and Mare 2015). Let C1 denote a birth cohort of individuals who either become parents $(G 1)$ or remain childless $(C L 1)$. Total cohort size is defined as $N^{C 1}=$ $N^{G 1}+N^{C L 1}$. Let $G 2$ denote the progeny of cohort $C 1$. The number of children in $G 2$ who attain educational level $i$ and have a parent $G 1$ with educational level $j$ is then given by 


$$
N_{i j}^{G 2}=N_{j}^{C 1} \cdot r_{i j}
$$

the total number of children who attain education level $i$ is given by

$$
N_{i .}^{G 2}=N_{j}^{C 1} \cdot r_{i j}+N_{j^{\prime}}^{C 1} \cdot r_{i j^{\prime}}
$$

and the total number of children is given by

$$
N^{G 2}=N_{i}^{G 2}+N_{i^{\prime}}^{G 2}
$$

This allows us to recover the educational mobility table from G2's perspective:

\section{G2 education}

G1 (parent) education

$$
\text { Low }
$$

High

Total

\begin{tabular}{cccc}
\cline { 2 - 3 } Low & $N_{L}^{C 1} \cdot r_{L L}$ & $N_{L}^{C 1} \cdot r_{H L}$ & $N_{. L}^{G 2}=N_{L}^{C 1} \cdot F_{L}$ \\
High & $N_{H}^{C 1} \cdot r_{L H}$ & $N_{H}^{C 1} \cdot r_{H H}$ & $N_{. H}^{G 2}=N_{H}^{C 1} \cdot F_{H}$ \\
\cline { 2 - 3 } Total & $N_{L .}^{G 2}$ & $N_{H .}^{G 2}$ & $N^{G 2}$
\end{tabular}

These analytical tools are useful to estimate the number of offspring, the distribution of education, and inequality in educational opportunity (e.g., via odds ratios obtained from G2's mobility table). Also, we can use these models for scenario analyses which allow us to assess, for example, how educational mobility patterns of $G 2$ would differ if higher educated persons of $C 1$ had the fertility behaviour of lower educated persons. All of this enables us to explore the relative role of fertility and mobility in processes of educational reproduction.

\section{Using retrospective data for prospective designs}

With prospective data, all relevant quantities can be estimated directly. In the following, we describe how retrospective data can be used to the same end. Building on previous work by Song and Mare (2015), we propose a method that addresses two issues related to retrospective 
data: (1) the problem of identifying a population to which findings can be generalized, and (2) the problem of retrospective sampling bias, i.e., the exclusion of childless individuals and the over-representation of parents with more (living) offspring. Our solution involves three steps. First, we define a birth cohort $C 1$ of individuals who may or may not become parents (demographic pathway) and who may or may not transmit their social position to children (social pathway). Second, we define a retrospective sampling strategy to identify this cohort of individuals. Third, we apply inverse probability weighting to adjust retrospective data in a way that minimizes retrospective sampling bias.

\section{Identifying a previous cohort using retrospective data}

In a representative cohort sample, all individuals of a cohort range under study have the same probability (random sample) or a known probability (probability sample) of inclusion. Assume that we have survey data representative of $G 2$ respondents aged 20 to 65 in the year 2010 (i.e., born between 1945 and 1990). Data are available on respondents' (G2) education and their parents' $(G 1)$ education and year of birth. Using these data, we aim to reconstruct a representative cohort $C 1$ that comprises parents $(G 1)$ as well as people who remained childless (CL1) and that adjusts for the overrepresentation of higher-parity parents in G1. A probability sample of target population $C 1=G 1+C L 1$ will be reconstructed from retrospective data in two steps.

The first step is identifying G1 using respondent data as anchor data. A key challenge is to restrict the respondent sample $G 2$ in way that it reflects a probability sample of $G 1$ 's offspring. Hence, identifying $G 1$ requires an assumption about $C l$ 's reproductive years - the life span during which $C 1$ could have procreated - ensuring that members of $C 1$ who eventually became parents $(G 1)$ have a non-zero probability of inclusion in the respondent data. To illustrate, we assume a reproductive period of 30 years both for men and women (ages 15 to 45). Note that this period can be defined separately for men and women and informed 
empirically by fertility data on relevant populations. Based on the reproductive period, we restrict the respondent sample to those whose parents were born within a historical period defined by a left limit of 1930 (1945 - 15; birth year of oldest respondent minus minimum reproductive age) and a right limit of 1945 (1990 - 45; birth year of youngest respondent minus maximum reproductive age). The resulting subsample of respondents refers to offspring that individuals born between 1930 and 1945 could have produced ( $G 2$ offspring of the population $C 1)$. This procedure, conducted separately for men and women, identifies $G 1$ mothers and $G 1$ fathers, corresponding to two $G 2$ samples as anchor data (offspring of mothers and offspring of fathers, respectively).

In the absence of restrictions on parents' birth years, the data would not be representative of parent cohorts. For example, if the respondent sample included parents born in 1915, these parents would not be representative of parents of the 1915 cohort because cohort members who became parents before 1945 (i.e., the lower bound of the respondent sample) are excluded from the respondent data. Demographically informed cohort restrictions imposed on the respondent sample minimize bias in the anchor data for $G 1$ parents.

To avoid right-censoring bias in $G 2$ (educational attainment increases over time), we define a minimum observation period of 20 years after birth. This restriction implies that we need to follow up parents until the age of 65 years to ensure that (a) the fertility process in the parent generation is complete and (b) the process of educational attainment in the offspring generation is (nearly) complete. Moreover, this restriction implies a lower age bound of 20 in the respondent sample $G 2$. In our example, this condition is met by respondents born between 1945 and 1990 and surveyed in 2010. Appendix Figure A1 summarizes the logic of sample selection.

Given these age bounds, G2 respondents represent anchors to $G 1$ parents born between 1930 and 1945. This cohort satisfies three important criteria: (1) Reproductive age criterionmembers of this cohort can produce children G2 born between 1945 (minimum reproductive 
age of 15) and 1990 (maximum reproductive age of 45); (2) uncensored fertility criterion - the process of fertility is complete for all members of this cohort; it is not left-censored (i.e., no children can be born before the oldest respondent) and not right-censored (i.e., no children can be born after the youngest respondent); (3) time-to-attainment criterion - the youngest child born to members of this cohort is old enough to complete the process of educational attainment.

Calibrating the anchor sample based on these criteria is essential to minimize bias in estimates of educational reproduction. If the respondent sample is too old (e.g., older than 65 at the time of survey), differential mortality in $G 2$ may introduce bias in $G 1$, for example, if children of higher educated parents are more likely to survive until the interview date. If the respondent sample is too young, Cl's incomplete fertility (e.g., underrepresentation of older parents in G1) and G2's incomplete attainment process (right-censoring in G2's attainment variable) may introduce bias. Additionally, caution is warranted in setting the lower cohort limit of G1. For example, consider extending the G1 cohort range from 1930-1945 to 1920-1945 by defining a minimum fertility age of 25 . The resulting $G 2$ sample would disproportionately consist of younger siblings (as later-born children are more likely to enter the respondent sample), biasing the $G 1$ data towards parents with higher and/or later fertility.

\section{Minimizing retrospective sampling bias}

After defining a cohort range for $C 1$, the anchor data on $G 1$ is still not yet representative of $C l$. It is still biased by the retrospective nature of the respondent data. First, data on higher-parity parents are overrepresented, as their children are more likely to be included in the anchor data. Second, childless members $C L$ of cohort $C 1$ are not accounted for in the anchor data. To adjust the sampling frame accordingly, we use a two-step method proposed by Song and Mare (2015) that introduces two correction factors: (1) the number of children of each respondent's family of origin, and (2) the fraction of childless individuals born between 1930 and 1945. The first factor can be obtained from data about respondents' $(G 2)$ number of siblings (available in many 
surveys), allowing us to correct for the overrepresentation of data from higher-parity parents by calculating weights for family size:

$$
w_{k}=\frac{1}{f_{k}}
$$

where $k$ is an enumerator for respondents and $f_{k}=s i b l_{k}+1$, i.e., the number of siblings plus the respondent. After applying these weights, a $G 1$ parent's number of children is unrelated to the probability of being included in the retrospective respondent data. This technique is a special case of inverse probability weighting used to account for sample selection bias (Hernan, Hernandez-Diaz, and Robins 2004).

Reweighting the retrospective respondent data yields prospective pseudo-data on $G 1$. We can now calculate G1's educational reproduction rate in two steps. First, we estimate $P_{j i \mid f}$ on the unweighted G2 sample using a logistic regression model (alternative models are possible). These are retrospective estimates of educational mobility in $G 2$, i.e., the probability that a child attains $j$ given the parent's attainment $i$ and family size $f$. Second, we approximate the conditional prospective educational reproduction rate (equation 2) by calculating

$$
\hat{r}_{j i \mid f>0}=\frac{1}{\sum_{k}^{n_{i}} w_{k}} \sum_{k}^{n_{i}} w_{k} f_{k} P_{j i \mid f}=\frac{1}{\sum_{k}^{n_{i}} w_{k}} \sum_{k}^{n_{i}} P_{j i \mid f}
$$

where $n_{i}$ is the number of respondents whose parents have educational level $i$. The formula shows that by means of re-weighting we effectively adjust the denominator of the mean expression to equal the sum of the family size weights instead of the sum of respondents.

The second correction factor adjusts for childlessness in $C 1$ (CL1). There are two ways of estimating childlessness for individuals born between 1930 and 1945. First, we could estimate the probability based on younger cohorts of respondents from the same dataset, a technique proposed by Song and Mare (2015). This method assumes that childlessness does not change substantially across cohorts, given that estimates for the probability of never having 
children are calculated for respondents born between 1945 (the oldest cohort) and 1960 (1945 plus 15 years) and then imputed for cohort $C 1$ born between 1930 and 1945 . Second, we could estimate fractions of childlessness across educational groups and gender on the basis of external fertility data covering the target cohort $C 1$ (Buis et al. 2012). Estimates for childlessness can be calculated by logistic regression accounting for group characteristics $X$ of the parent generation (e.g., gender, educational level, year of birth):

$$
\operatorname{Pr}(f=0 \mid X)=\Lambda(X)
$$

Using group characteristics $X$, estimated probabilities can be matched to the anchor data to obtain complete weights that adjust for retrospective sampling bias:

$$
f w_{k}=w_{k} \cdot \frac{1}{1-\operatorname{Pr}(f=0 \mid X)}
$$

Using these weights, we can recover marginal distributions of educational levels that are representative of the population of individuals $C 1$ born between 1930 and 1945. Furthermore, by combining external data on group-specific childlessness and anchor data on family size, we can estimate cohort fertility for men and women of different educational groups. Group-specific estimates for childlessness allow us to approximate our main outcome of interest, the unconditional educational reproduction rates of $C 1$ (equation 3) by

$$
\hat{r}_{j i}=[1-\operatorname{Pr}(f=0 \mid i)] \cdot \hat{r}_{j i \mid f>0}
$$

Note that educational reproduction rates are calculated separately for $C 1$ women and $C 1$ men using the gender-specific offspring samples described above. 


\section{Educational reproduction in East and West Germany}

To illustrate our method, we examine educational reproduction in East and West Germany. We used pooled cross-sectional data from two datasets containing retrospective respondent-parent data on social mobility, Starting Cohort 6 the German National Educational Panel Study (NEPS SC6) and the German Socio-Economic Panel Study (SOEP). Pooling is not necessary for the method we apply, but it improves the precision of the estimates.

Starting Cohort 6 of the NEPS (Blossfeld, Roßbach, and von Maurice 2011) comprises individuals born between 1944 and 1988 that have been followed up annually since 2009 or 2010. To maximize case numbers, we selected the fourth wave of $2011 / 2012$, which includes a refreshment sample in addition to the original sample. The SOEP is an annual panel survey of households and individuals started in 1984. Currently it provides data on up to 32 panel waves per respondent. We selected a cross-section from the year 2012 that is highly comparable to the NEPS sample. Over time, the SOEP was augmented by several refreshment samples and oversamples. We kept only subsamples that are part of the overall probability sample of persons living in German households.

We measured education by a dichotomous measure of having an Abitur degree (upper secondary schooling degree in Germany) or not. Although more detailed data on educational levels (e.g., years of education) were available, we used a dichotomous measure for three reasons. First, Abitur degrees are comparable across generations, across East and West Germany, and, in terms of measurement, comparable across the two datasets that partly used different coding schemes. Second, although entry into higher education in Germany has become more flexible in recent decades, the Abitur degree has been and still is the major route into university. This means that the dichotomy captures a highly relevant aspect of educational inequality and path dependency of educational careers in Germany. Third, Abitur is usually completed at age 18 or 19, after 13 years of schooling in a more (West) or less (East) stratified school system. As a result, our measure is less affected by issues of right-censoring than other 
measures of highest educational attainment. This benefit was crucial for our purposes because it allowed us to reduce the minimum length of the observation window (see above).

Both datasets provide data on education in the respondent generation $G 2$ and in the parent generation $G 1$. From these anchor data, we reconstructed a representative cohort $C 1$ of individuals born in East and West Germany between 1930 and 1945. To accomplish this, we used respondent information on year of birth, sex, number of siblings, and highest educational level. In addition, we used information provided by the respondents on both parents, including their highest educational level, year of birth, immigrant status (i.e., born in Germany or not), and whether they lived in East or West Germany before reunification in 1989. All measures were harmonized across datasets.

\section{Selecting a starting sample of respondents}

In a first step, we defined a starting sample of respondents, removing all cases with missing information on respondent or parent variables. Next, we restricted the SOEP sample to cover an interval of birth cohorts that was identical to the NEPS. This yielded a sample size of 28,526 respondents. Because this sample was drawn from panel studies, we used weights that both surveys provide to adjust for non-random sampling and attrition. Our respondent sample was representative of non-institutionalized persons born between 1944 and 1988. Table 1 shows descriptive statistics separately for both datasets and the pooled data.

\section{$===$ TABLE $1==$}

The distribution of parent variables shows that these data were representative of (parental) conditions in which respondents grew up, but not for any population that could be identified prior in time. For example, the birth years of parents spanned almost one century (1877 until 1972). Even when looking only at the span between the $5^{\text {th }}$ and the $95^{\text {th }}$ percentile, the cohort 
spans remained large, ranging from 1914 to 1960 for mothers and from 1910 to 1957 for fathers. Moreover, fathers were on average 3 years older than mothers, reflecting age preferences in assortative mating (Skopek, Schmitz, and Blossfeld 2011). This means that from an unadjusted retrospective view, fathers come from older birth cohorts than mothers. Furthermore, the average number of siblings was 1.8, suggesting an average number of almost 3 children per parent - much higher than what demographic data show for the respective target cohort $C 1$ of East and West Germans (Kreyenfeld 2003). Finally, the retrospective nature of the data misrepresents the relation between children and their parents. Each case is treated as having two parents, although in the population, siblings have the same parents. Figure 1 illustrates these issues for the example of respondents born between 1970 and 1980.

\section{$===$ FIGURE $1===$}

\section{Identification of target cohorts}

To identify cohort $C 1$, we applied the two procedures described above. First, we restricted the sample to cover an identifiable cohort that included the parents of respondent sample $G 2$ (born between 1944 and 1988). As explained above, this restriction satisfies the three criteria described above: (a) the fertility process could have produced $G 2$, (b) the fertility process was complete, and (c) sufficient time had elapsed for $G 2$ to complete their attainment process. The lower bound of the cohort range for $C 1$ (1930) was defined by a minimum age at parenthood of 14 years. The upper bound of the cohort range for C1 (1945) was demographically informed by population data showing that having a child after age 40 is rare in women (Billari et al. 2007) and also in men (Prioux 2005). In our sample, $99 \%$ of respondents' mothers and $96 \%$ of fathers were aged 43 or younger when their child (i.e., the respondent) was born. Weighing the extent of possible bias against cohort coverage of $C 1$, we used age 43 as the upper bound for both men and women, hence setting the upper cohort limit at 1945. 
Based on these restrictions, we defined G1 parent samples of target cohorts $C 1$ (19301945) separately for mothers and fathers. For the mother sample we selected respondents who met three criteria: (1) their mother was born between 1930 and 1945; (2) their mother was born in Germany; (3) their mother's educational level was known. For the father sample, we applied analogous restrictions. We further split the mother and father samples into East and West Germany based on the information obtained from the respondents, assuming that parents born between 1930 to 1945 spent their life in the part of Germany in which the respondent was born. After identifying the target cohorts, we used a variable for respondents' number of siblings to create family size weights (see equation 19) which adjust for part of the retrospective sampling bias.

\section{Matching external fertility data}

As the $C 1$ samples were still restricted to parents, we used external data to consider also childless individuals of $C 1$. In their analysis of U.S. data, Song and Mare (2015) argued that matching of external data is difficult because retrospective parent data are not representative. Instead, they recommend estimating childlessness on the basis of offspring data, assuming that childlessness did not change across generations. In our case, this assumption cannot be defended because levels of childlessness in East and West Germany changed substantially across the relevant study cohorts (Kreyenfeld 2003). Furthermore, our method identifies a representative parent cohort, allowing us to match external fertility data based educational level, part of Germany, gender, and year of birth.

To increase precision of fertility estimates for the cohorts under study, we pooled external fertility data from several surveys providing data on the relevant variables: childlessness, educational level, date of birth, born in Germany, and having lived in East or West Germany. In total, we used 16 surveys, including 12 repeated cross-sections from the German General Social Survey (ALLBUS), starting and refreshment samples from 3 waves of the German 
Ageing Survey (DEAS), and the German sample of the European Social Survey (ESS) from 2006. From these surveys, we retrieved a total of 13,109 respondents $(N=4,253$ for East Germany, $N=8,856$ for West Germany) born between 1930 and 1945 and providing information on all relevant variables. Table A1 in the Appendix provides an overview of the surveys.

Next, we used a joint logit model with interaction terms to predict probabilities of being childless by cohort groups (1930-35, 1936-40, and 1941-45), part of Germany (East or West), gender, and educational level. The model adjusted for survey effects and accounted for right censoring in the observed fertility process by adjusting for age at interview. The detailed model specification is shown in the Appendix (equation A1). Table 2 shows the levels of childlessness as predicted by the logit model for the cohorts under study. In a final step, we matched these probabilities to the G1 parent samples, based on cohort, gender, educational level, and part of Germany.

\section{$===$ TABLE $2==$}

\section{Results}

Table 3 presents the results of each step in defining a target cohort $C 1$. Panel A shows mean values for mothers' and fathers' attributes before adjustment (G2's perspective); panel B shows mean values after adjusting for parents' birth years and family size (G1's perspective); panel C shows mean values after adjusting for parents' birth years, family size, and childlessness (Cl's perspective). Because of retrospective sampling bias, the unadjusted data in Panel A overestimate fertility of fathers and mothers (almost 3 children on average) and slightly underestimates educational levels. 
Cohort fertility rates of women shown in Panel $\mathrm{C}$ almost perfectly match official data for these cohorts (for women born 1930-1945 our estimate was 1.96, compared to 2.03 reported in official data, Statistisches Bundesamt 2017). There are no official fertility data for men, but our method estimates cohort fertility rates of men born 1930-1945 slightly lower than women's fertility rates. The difference is explained by higher levels of childlessness in men $(15.1 \% \mathrm{vs}$. $13.2 \%$ in women) and a slightly lower average number of children for fathers. Note that men born between 1930 and 1945 were married to women who were on average 2 to 3 years younger, a population that is different from our $C 1$ cohort of women (and vice versa).

Figure 2 illustrates distributions of birth years for all relevant samples. For parents and childless persons, the distribution is restricted to an interval between 1930 and 1945, for children to an interval between 1945 and 1988. The figure shows that our design yields cohort distributions that approximate historical population data, which are located in the Appendix (Figure A2).

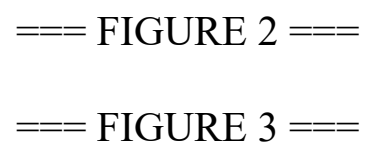

Figure 3 presents patterns of educational stratification in terms of upper secondary schooling across two generations separately by gender and part of Germany. In the upper panel for cohorts born between 1930 and 1945, we see that women's disadvantage in education remained stable across cohorts in the West, whereas the gap closed across cohorts in the socialist system of East Germany. In these cohorts, educational levels were generally higher in the East than in the West, particularly among women. The lower panel for the offspring of these cohorts $(G 2)$ shows a strong increase in educational attainment across cohorts, reflecting rapid educational expansion, especially in West Germany. For offspring born after 1970, educational careers were increasingly completed in a unified Germany, as indicated by converging rates of 
educational attainment in both parts of the country. Note, however, that the offspring data by construction is no longer representative for individuals born between 1944 and 1988. Given that higher education postpones fertility to later ages, the strong increase in G2's educational levels also reflects differential timing of childbearing in $C 1$.

\section{Educational reproduction of men and women in Germany}

Table 4 and 5 show our estimates for educational reproduction in East and West Germany. We start with conventional retrospective estimates for educational mobility to predict chances of attaining higher education in $G 2\left(P_{j i \mid f}\right.$, see equations 1 and 20). We estimated logistic regression models that condition on parents' education and family size separately for all offspring samples in East and West Germany. ${ }^{6}$ Additionally, we adjusted for differences between surveys in the outcome.

Table 4 presents results in the form of logit coefficients and average marginal effects. In West Germany, children of higher educated parents were almost 50 percentage points more likely to attain higher education than children of lower educated parents. In East Germany, this effect was smaller, amounting to a 32 percentage-points increase. Family size effects were substantial in both parts of Germany. Chances of attaining higher education decreased, on average, by 4 to 6 percentage points for each additional child in the family. This result demonstrates the importance of family size for our main analysis: A higher number of children strengthens population-level reproduction, but it weakens family-level reproduction through negative effects on children's educational attainment. Analyses that omit family size would therefore overestimate educational reproduction of parents that have a higher number of children. 
In Table 5, we present prospective estimates that combine mobility and fertility components of educational reproduction. The data in the table, pertaining to target cohort $C 1$ born between 1930 and 1945, are divided into three panels. The first panel shows fertility estimates, the second panel summarizes aggregate mobility estimates, and the third shows combined estimates for the expected number of higher and lower educated children.

Consistent with previous demographic research (e.g., Kreyenfeld 2004), the fertility estimates revealed the strongest educational gradient in fertility among West German women - a pattern that is driven mainly by educational differences in childlessness. An estimated 23 \% of women who were born between 1930 and 1945, grew up in West Germany, and attained higher education remained childless, compared to only $13 \%$ for their lower educated counterparts. Conditioning on motherhood, the number of children was also higher among lower educated women (2.28 vs. 2.14).

Among West German men educational gradients in fertility were much smaller, as we found no differences in childlessness. Lower educated fathers slightly surpassed higher educated fathers in the number of children (2.24 vs. 2.11). In East Germany, rates of childlessness were lower, although family size was slightly smaller across all educational groups. In East German women, the higher educated more often remained childless, but the reverse was true in men. Conditioning on parenthood, we found similar educational gradients, whereby lower educated mothers and fathers had slightly more children than their higher educated counterparts.

The second panel of Table 5 shows summarized mobility estimates in terms of marginal rates of children attaining higher education aggregated over the distribution of family size (probabilities and odds ratios predicted based on the models shown in Table 4). On average, approximately $80 \%$ of children of higher educated parents reached higher levels of education, 
compared to approximately $30 \%$ of children of lower educated parents. For East Germany, this difference was smaller (55\% vs. $20 \%$ ).

The third panel of Table 5 presents our key estimates of interest, showing for rates of educational reproduction (equation 3), joint effects (equation 4), and decomposition results (equations 6 and 11) for two outcomes - the production of children with higher and lower education. ${ }^{7}$ Table A2 in the Appendix shows estimates for factual and counterfactual rates underlying the decomposition. We obtained standard errors by a non-parametric Jackknife resampling method (Efron and Stein 1981) and used a conservative alpha level $(\mathrm{p}<.01)$ for statistical inference.

On average, higher educated West Germans produced 1.4 higher educated children and lower educated West Germans produced 0.6 higher educated children. The joint demographic and mobility effects in rates of producing higher educated offspring are similar between West German women (0.75) and men (0.83), but a decomposition reveals that fertility and mobility mechanisms differed by gender in generating a similar educational reproduction outcome. Differential fertility was negligible for men's production of higher educated offspring, but it tempered educational reproduction of women. In the absence of educational differences in women's fertility, the joint effect (i.e., the absolute difference in the number of higher educated children) would be $20 \%$ larger amounting to 0.9 instead of $0.75(\mathrm{p}<.01)$. Differential fertility thus dampened the mobility effect by $16.7 \%$. In higher educated men, the production of higher educated children was hardly affected by educational differences in fertility.

Looking at the reverse outcome, the production of lower educated children in West Germany, results showed that fertility reinforced the mobility component. Differences in joint effects would be smaller (by 0.17 for women and by 0.09 for men) if fertility differences between higher and lower educated men and women were cancelled out. Again, the fertility component was more relevant for West German women than for West German men. 
Among target cohorts $C 1$ of East Germans, rates of educational reproduction and joint effects were smaller. East German women's educational reproduction was tempered by differential fertility, but this component was weaker $(-12 \%$ of the total effect) than in West German women. On the other hand, fertility differences amplified the mobility effect with respect to the production of lower educated offspring. Among East German men, partial effects of fertility components for both outcomes were small in size and not statistically significant.

We estimated additional models for a dichotomous outcome of producing at least one child with higher education, a probability metric used by Lawrence and Breen (2016). We calculated probabilities using stochastic rules (see equation A2). The findings from these models are shown in the Appendix (Table A3). In Figure 4, we illustrate selected results from count and probability metrics for the example of women's educational reproduction in West Germany.

\section{$===$ FIGURE $4===$}

A general finding from our models is that higher educated women reproduced their education to a smaller extent than conventional educational mobility estimates would suggest. In contrast to prospective estimates, retrospective measures would suggest that educational reproduction was stronger for women in West Germany and did not differ by gender in East Germany (see odds ratios in Table 5). For our study cohorts, however, lower fertility limited higher educated women in passing their educational advantage on to the next generation.

\section{Consequences of differential fertility for inequality in the offspring generation}

Consistent with previous research using prospective data, our method demonstrated that lower fertility limits educational reproduction in higher educated individuals. In a final step of the analysis, we examined how this tempering effect of fertility influenced the distribution of 
education, and social inequality therein, in the offspring generation. Based on population renewal models (equations 16-18), we simulated the proportion of $G 2$ attaining higher education as well as educational inequality, indicated by the association with parents' education. The results of the simulation are shown in Table 6 .

\section{$===$ TABLE $6==$}

The data in Table 6 show four hypothetical scenarios in which distributions and parameters were exchanged for educational groups in G1. To calculate distributions in $G 2$, we multiplied the relative sizes of educational groups in $G 1$ with the estimated factual and counterfactual rates of educational reproduction, the latter of which link educational distributions across generations.

In our interpretation of the results, we focus mainly on West German women - the group in which fertility differed most strongly by education. If higher educated West German women in $G 1$ had the fertility distribution of lower educated West German women (Scenario 1), we would expect the share of higher educated persons in $G 2$ to increase by 0.3 percentage points from 34.9 to $35.2 \%$. Conversely, if lower educated women had the fertility of higher educated women (Scenario 2), 37.1 per cent of children in $G 2$ would attain higher education. In these scenarios, the relative sizes of the offspring population vary considerably (198\% in Scenario $1,165 \%$ in Scenario 2), but the impact of differential fertility on the distribution of education in $G 2$ is relatively small. In both counterfactual scenarios, educational inequality measured by odds ratios would be lower. These differences emerge from fertility effects on the family level, i.e., negative effects of the number of siblings on children's educational attainment. These results of the simulation are particularly interesting when interpreted jointly: If higher educated mothers had the same fertility as lower educated mothers (Scenario 1), this would not only 
mean that more children would be born and a slightly higher share of children would reach higher education, but also that educational inequality would be smaller.

In general, however, the first two scenarios show that the association between education and fertility in $G 1$ was too weak to substantially impact on the distribution of educational or educational inequality in G2. This was true even in West German women who showed the largest educational gradient in fertility. We note, however, that small differences in a twogenerational model of population renewal would accumulate rapidly when further extrapolated to future generations.

Scenarios 3 and 4 simulate the same quantities for counterfactual rates of mobility. As per the exchange of parameters, inequality would disappear almost entirely, although children of higher educated parents would still enjoy slight advantages due to family-level effects of differential fertility (i.e., educational advantage of having fewer siblings). Taken together, the simulation results show that the distributions of education in $G 1$ and in $G 2$ are more strongly linked by mobility as a social pathway than by fertility as a demographic pathway.

\section{Discussion}

Extant prospective studies of intergenerational reproduction have used designs that placed high requirements on the data. As only few datasets meet these requirements, prospective perspectives remain sidelined in research on the intergenerational reproduction of education. The first and main contribution of the present study is to introduce a method that allows estimating prospective models of intergenerational reproduction based on retrospective data. This method places fewer demands on the data, as it requires only variables that are available in many cross-sectional and longitudinal surveys.

Two further general contributions of our study were that our model specified fertility effects on the population level and on the family level, addressing two pathways of fertility effects on educational reproduction, and that our model was demographically informed by 
external fertility data. Instead of assuming that childlessness did not change across generations (Song and Mare 2015), we identified a representative parent cohort and matched external fertility data.

We illustrated the method using data on East and West German respondents, linking the respondent generation to earlier birth cohorts (1930-45) of potential parents, and minimizing retrospective sampling bias arising from differential fertility. Our results show that the extent to which conventional estimates of educational reproduction change when viewed through a prospective lens depends on the social and demographic context. The largest differences emerged for West German women, the group in which the association between education and fertility was strongest. Higher rates of childlessness and a lower number of children limited the educational reproduction of higher educated West German women. These women produced an expected number of 1.4 higher educated children -0.75 more than their lower educated counterparts. Yet, this difference would have been larger (0.90) in the absence of educational differences in fertility, suggesting that differential fertility weakened educational reproduction by $20 \%$.

For East German women, the fertility effects pointed in the same direction, but was less pronounced. In men, fertility hardly affected educational reproduction. These findings for men demonstrate the similarity of conclusions on educational reproduction produced by retrospective and prospective designs if the association between education and fertility is weak.

A fourth contribution of our study was to provide a better assessment of the consequences of demographic and social processes underlying the reproduction of social inequality across generations. Our simulations based on population renewal models revealed that differential fertility lowered educational attainment and increased inequality in educational attainment in the offspring generation. Yet, the total effect of differential fertility was small for the cohorts studied in our example. Taken together, our results for the German context suggest 
that status transmission within families was the major mechanism in educational reproduction, although this process was also shaped by demographic pathways.

The method proposed in this paper shows that analysts of social stratification can utilize their common data sources to complement retrospective designs by prospective designs of intergenerational reproduction. In addition to the standard variables used in mobility tables, the only additional variables required for estimating a simple prospective model are the birth years of parents and the number of siblings. These variables are usually available in large-scale multipurpose surveys, suggesting that the method we propose is broadly applicable.

We close with a number of limitations and directions for future research. First, our method is not feasible for studies on the causal impact of education (Breen and Ermisch 2017; Lawrence and Breen 2016). That would require valid data on important confounders such as academic achievement or social class background (of parents) which is are usually not available in retrospective data. Similar to other widely used methods in social mobility research, our approach is suitable for analyses on associations and trends in intergenerational reproduction as well as cross-national comparisons. Given that our method places few demands on the data, it opens up new avenues for research along these lines.

Second, the availability of high-quality external data on fertility could limit applications. Note, however, that our method does not rely on external data on childlessness. Two alternative strategies are possible. Researchers could estimate childlessness based on a weighted respondent sample providing truncated (i.e., positive) fertility data on parents' number of children. Based on the assumption that decisions on whether and how many children are born are governed by one underlying process, Poisson models could estimate out-of-sample levels of childlessness conditional on education or other measures of socioeconomic status. Alternatively, researchers could estimate a target cohort's levels of childlessness using data from the same retrospective dataset, which may cover overlapping or adjacent cohorts. 
Third, a general limitation of prospective models is their extensive time span. Educational reproduction can only be assessed after the fertility process in $G 1$ is complete and the attainment process in $G 2$ is complete. In our study, we limited the analysis to school attainment, as more detailed measures (e.g., tertiary education) would require many additional years before educational careers are completed. Retrospective studies are more timely, because the range of study cohorts is not restricted by design. This benefit, however, comes with the disadvantage that any approach that looks backwards to parents ignores important mechanisms that link populations, and associated structures of inequality, to their offspring. In this regard, we consider it a promising direction for future mobility research to employ prospective models to forecast inequality in future populations.

\section{Notes}

1 Instead of the expected number of children in an educational category (reproduction rate $r_{i j}$ ), we could calculate the probability of having at least one child of educational level $i$. The probability metric resembles the concept of origin-specific chances (offspring's probability of attaining education $i$ conditional on parent's education $j$ ) from a prospective view (a person's probability of having at least one child of educational level $i$ conditional on the person's educational level $j$ ), as recently proposed by Lawrence and Breen (2016). We favored the count metric, but our design can approximate the probability metric using stochastic rules (see equation A2 in the Appendix).

2 We use the term counterfactual not in a causal sense, as our models do not allow us to estimate the causal effect of educational treatments. The goal of calculating counterfactual rates is to understand structural differences in rates of reproduction across educational groups.

3 Analogously it can be shown that $\Delta_{m}^{h}=\frac{1}{2}\left(h_{H L}-h_{L L}+h_{H H}-h_{L H}\right)$.

4 Proof involves the following:

$$
\begin{aligned}
& \Delta_{m}^{h}=\frac{1}{2}\left(h_{H L}-h_{L L}+h_{H H}-h_{L H}\right) \\
& =\frac{1}{2}\left[\left(F_{l}-l_{H L}\right)-\left(F_{l}-l_{L L}\right)+\left(F_{h}-l_{H H}\right)-\left(F_{h}-l_{L H}\right)\right]
\end{aligned}
$$


$=-\frac{1}{2}\left(l_{H L}-l_{L L}+l_{H H}-l_{L H}\right)=-\Delta_{m}^{l}$

5 This is an identifying constraint. The proof involves the following:

$\Delta_{f}^{h}=\frac{1}{2}\left(h_{L H}-h_{L L}+h_{H H}-h_{H L}\right)$

$=\frac{1}{2}\left[\left(F_{h}-l_{L H}\right)-\left(F_{l}-l_{L L}\right)+\left(F_{h}-l_{H H}\right)-\left(F_{l}-l_{H L}\right)\right]$

$=F_{H}-F_{L}-\Delta_{f}^{l}$

6 We used a linear specification of family size effects for reasons of parsimony. Alternative specifications yielded similar results.

7 Previous prospective research has focused only on the production of higher educated children, but there is no clear theoretical rationale justifying this restriction. 


\section{References}

Becker, Gary S. and Nigel Tomes. 1976. "Child Endowments and the Quantity and Quality of Children." Journal of Political Economy 84(4):143-62.

Billari, Francesco C., Hans-Peter Kohler, Gunnar Andersson, and Hans Lundström. 2007. "Approaching the Limit: Long-Term Trends in Late and Very Late Fertility." Population and Development Review 33(1):149-70.

Black, Sandra E., Paul J. Devereux, and Kjell G. Salvanes. 2005. "The More the Merrier? The Effect of Family Size and Birth Order on Children's Education.” The Quarterly Journal of Economics 120(2):669-700.

Blossfeld, Hans-Peter, Sandra Buchholz, Jan Skopek, and Moris Triventi, eds. 2016. Models of Secondary Education and Social Inequality: An International Comparison. Cheltenham, UK and Northampton, MA, USA: Edward Elgar.

Blossfeld, Hans-Peter, Hans-Günther Roßbach, and Jutta von Maurice. 2011. Education as a Lifelong Process - The German National Educational Panel Study (NEPS). Heidelberg: Springer VS.

Breen, Richard. 2004. Social Mobility in Europe. Oxford: Oxford University Press.

Breen, Richard. 2010. "Educational Expansion and Social Mobility in the 20th Century." Social Forces 89(2):365-88.

Breen, Richard and John Ermisch. 2017. "Educational Reproduction in Great Britain: A Prospective Approach.” European Sociological Review 1-14.

Breen, Richard, John Ermisch, and Satu Helske. 2017. "Educational Reproduction in Europe: An Analysis Using SHARE Data.”. Paper presented at the ISA RC28, spring meeting, Cologne.

Breen, Richard and Jan O. Jonsson. 2005. "Inequality of Opportunity in Comparative Perspective: Recent Research on Educational Attainment and Social Mobility.” Annual Review of Sociology 31(1):223-43. 
Breen, Richard, Ruud Luijkx, W. Muller, and R. Pollak. 2009. “Long-Term Trends in Educational Inequality in Europe: Class Inequalities and Gender Differences.” European Sociological Review 26(1):31-48.

Breen, Richard, Ruud Luijkx, Walter Müller, and Reinhard Pollak. 2009. "Nonpersistent Inequality in Educational Attainment: Evidence from Eight European Countries.” American Journal of Sociology 114(5):1475-1521.

Buis, Authors Maarten L., Bastian Mönkediek, and Steffen Hillmert. 2012. "Educational Expansion and the Role of Demographic Factors: The Case of West Germany.” Population Review 51(2):1-15.

Conley, Dalton and Rebecca Glauber. 2006. "Parental Educational Investment and Children's Academic Risk: Estimates of the Impact of Sibship Size and Birth Order from Exogenous Variation in Fertility." Journal of Human Resources 41(4):722-37.

Downey, Douglas B. 1995. "When Bigger Is Not Better: Family Size, Parental Resources, and Children's Educational Performance.” American Sociological Review 60(5):746-61.

Efron, B. and C. Stein. 1981. “Jackknife Estimate of Variance.” Annals of Statistics 9(3):58696.

Erikson, Robert and John H. Goldthorpe, eds. 1993. The Constant Flux: A Study of Class Mobility in Industrial Societies. Oxford: Clarendon Press.

Featherman, David L. and Robert M. Hauser. 1978. Opportunity and Change. New York: Academic Press.

Goldthorpe, John H. 1996. "Class Analysis and the Reorientation of Class Theory: The Case of Persisting Differentials in Educational Attainment.” British Journal of Sociology 47(3):481-505.

Haller, Max, ed. 1990. Class Structure in Europe: New Findings from East-West Comparisons of Social Structure and Mobility. Armonk: ME Sharpe.

Hernan, Miguel A., Sonia Hernandez-Diaz, and James M. Robins. 2004. “A Structural 
Approach to Selection Bias.” Epidemiology 15(5):615-25. Retrieved

(http://www.jstor.org/stable/20485961).

Hillmert, Steffen. 2013. “Analysing Intergenerational Transmissions: From Social Mobility to Social Reproduction.” Comparative Social Research 30(2013):131-42.

Jackson, Michelle. 2013. Determined to Succeed? Performance versus Choice in Educational Attainment. Stanford: Stanford University Press.

Kreyenfeld, Michaela. 2003. "Crisis or Adaptation - Reconsidered: A Comparison of East and West German Fertility Patterns in the First Six Years after the 'Wende."' European Journal of Population 19(3):303-29.

Kreyenfeld, Michaela. 2004. "Fertility Decisions in the FRG and GDR: An Analysis with Data from the German Fertility and Family Survey.” Demographic Research (Special Collection 3: Article 11):275-318.

Kye, Bongoh and Robert D. Mare. 2012. “Intergenerational Effects of Shifts in Women’s Educational Distribution in South Korea: Transmission, Differential Fertility, and Assortative Mating." Social Science Research 41(6):1495-1514.

Lawrence, Matthew and Richard Breen. 2016. "And Their Children After Them? The Effect of College on Educational Reproduction." American Journal of Sociology (March).

Maralani, Vida. 2013. “The Demography of Social Mobility: Black-White Differences in the Process." American Journal of Sociology 118(6):1509-58.

Mare, Robert D. 1997. "Differential Fertility, Intergenerational Educational Mobility, and Racial Inequality." Social Science Research 26(3):263-91.

Mare, Robert D. and Vida Maralani. 2006. "The Intergenerational Effects of Changes in Women's Educational Attainments." American Sociological Review 71:542-64.

Prioux, F. 2005. "Late Fertility in Europe: Some Comparative and Historical Data." Revue d'Epidémiologie et de Santé Publique 53(2005):1-9.

Sensch, Jürgen. (1847-2002 [2004]) histat-Datenkompilation online: Geschichte der 
deutschen Bevölkerung seit 1815 [Computer file] ZA8171, version 1.0.0. Cologne, Germany: GESIS Datenarchiv [distributor], 2004. doi:10.4232/1.8137.

Shavit, Yossi and Hans-Peter Blossfeld. 1993. Persistent Inequality. Changing Educational Attainment in Thirteen Countries. Boulder: Westview Press.

Skopek, Jan, Andreas Schmitz, and Hans-Peter Blossfeld. 2011. "The Gendered Dynamics of Age Preferences - Empirical Evidence from Online Dating." Zeitschrift fur Familienforschung 23:267-90.

Statistisches Bundesamt. 2017. "Endgültige durchschnittliche Kinderzahl der Frauenkohorten" [Cohort fertility of women's cohorts]. Wiesbaden, Germany: Statistisches Bundesmant (Federal Statistical Office). Retrieved August 21, 2017 (https://www.destatis.de/DE/ZahlenFakten/GesellschaftStaat/Bevoelkerung/Geburten/Ta bellen/EndgueltigeKinderzahl.html)

Song, Xi and Robert D. Mare. 2015. "Prospective Versus Retrospective Approaches to the Study of Intergenerational Social Mobility." Sociological Methods \& Research 44(4):555-84. 
Figures

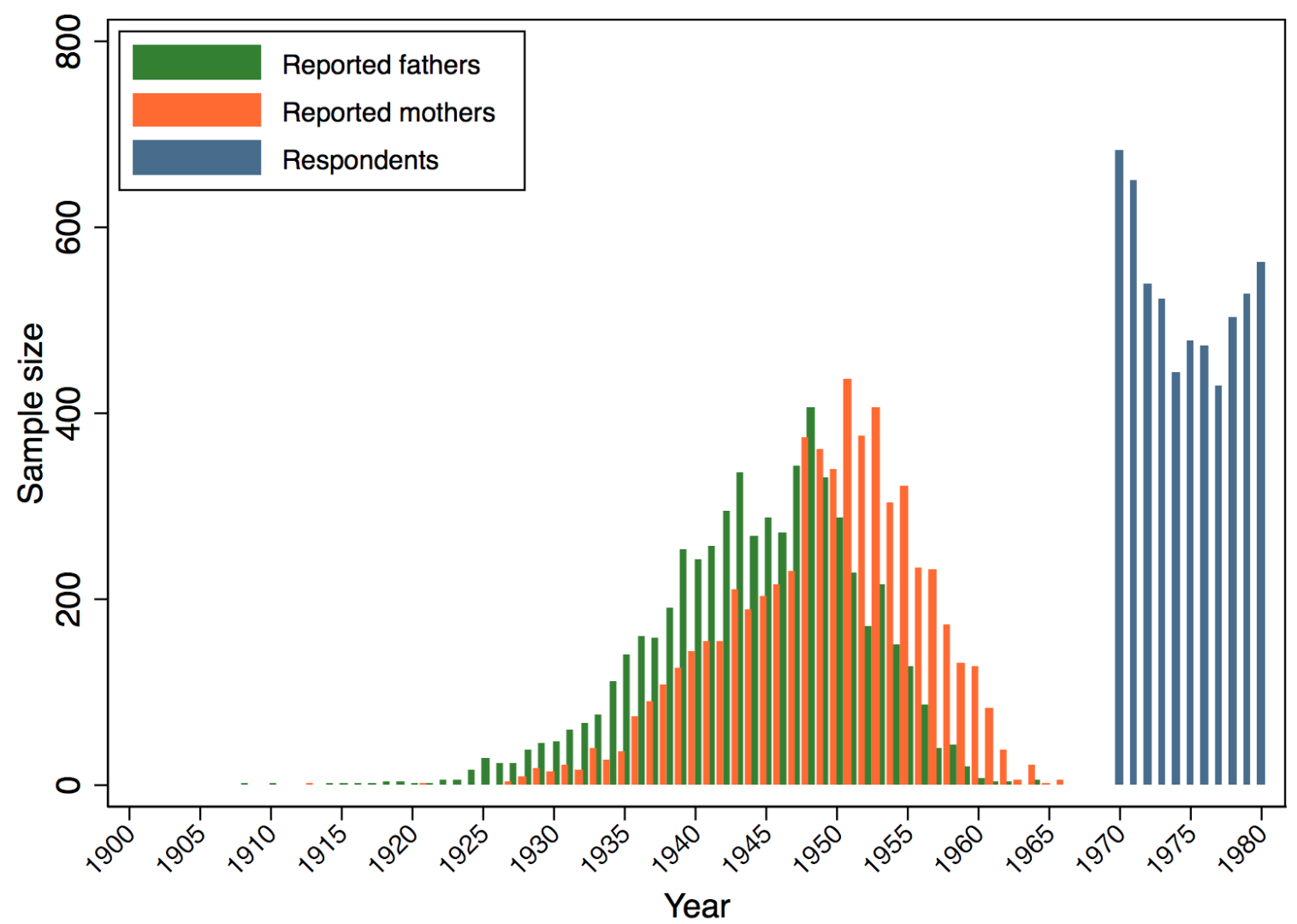

FIGURE 1. RESPONDENTS AND THEIR PARENTS FROM A RETROSPECTIVE VIEW

Note: Data are from NEPS and SOEP (pooled). Illustration for respondents born 1970-1980. 

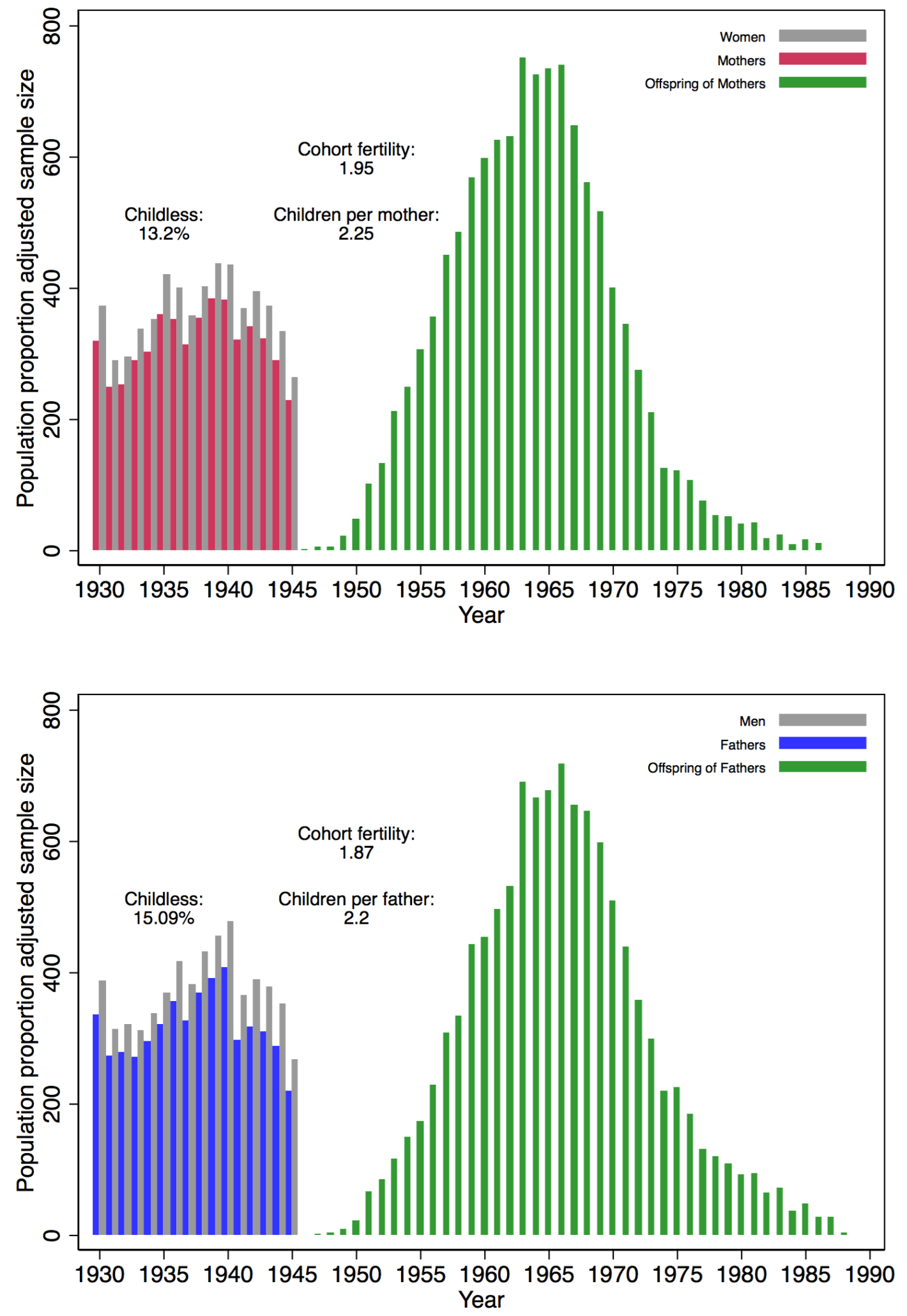

FIGURE 2. INDIVIDUALS BORN 1930-1945 IN GERMANY - PARENTS AND THEIR OFFSPRING RECONSTRUCTED FROM RETROSPECTIVE DATA

Note: Data are from NEPS and SOEP (pooled). 

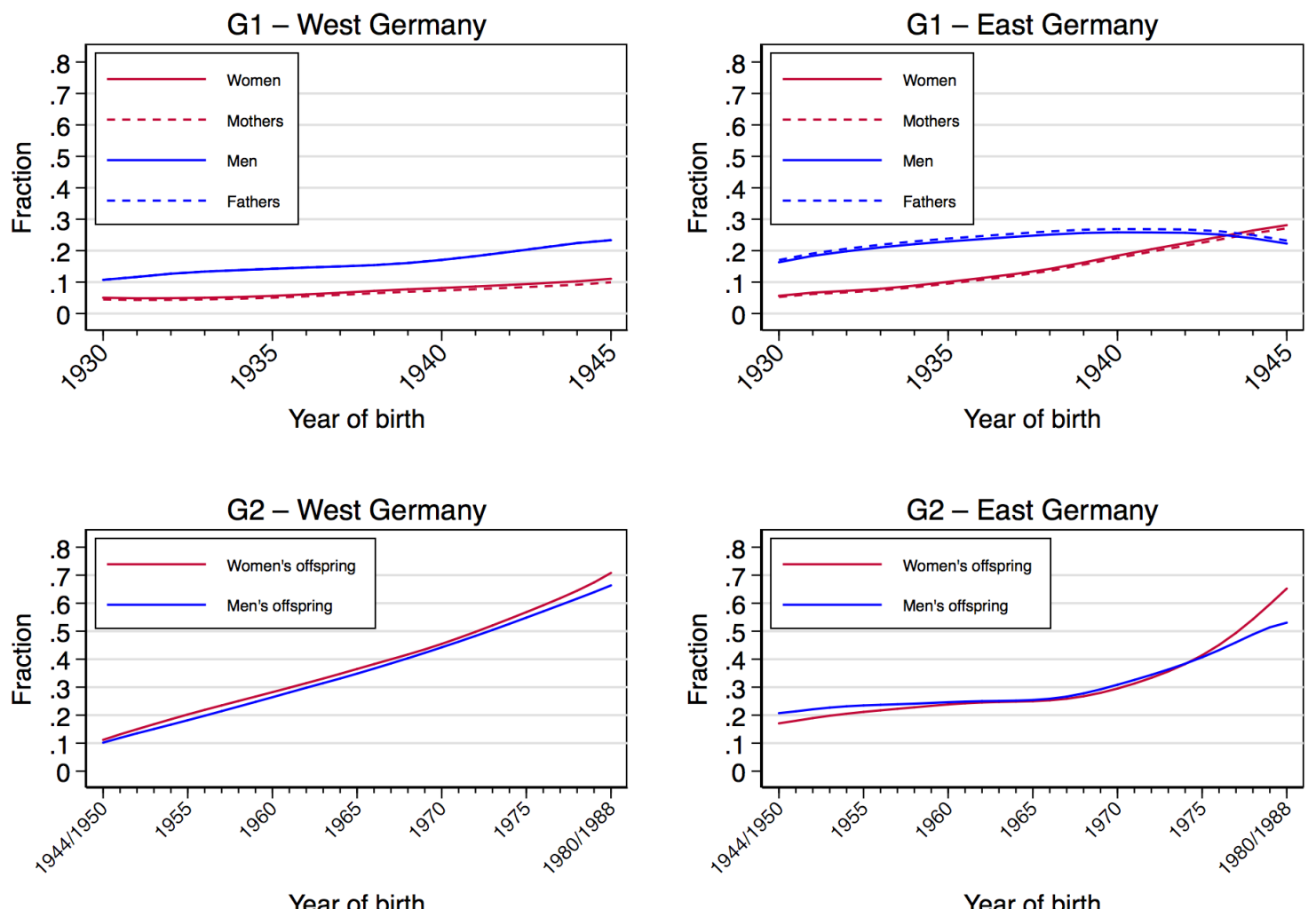

FiguRE 3. EDUCATIONAL ATTAINMENT OF INDIVIDUALs BORN 1930-1945 (G1) AND THEIR OFFSPRING (G2)

Note: Data are from NEPS and SOEP (pooled). Fractions of higher educational attainment (Abitur) are shown. 


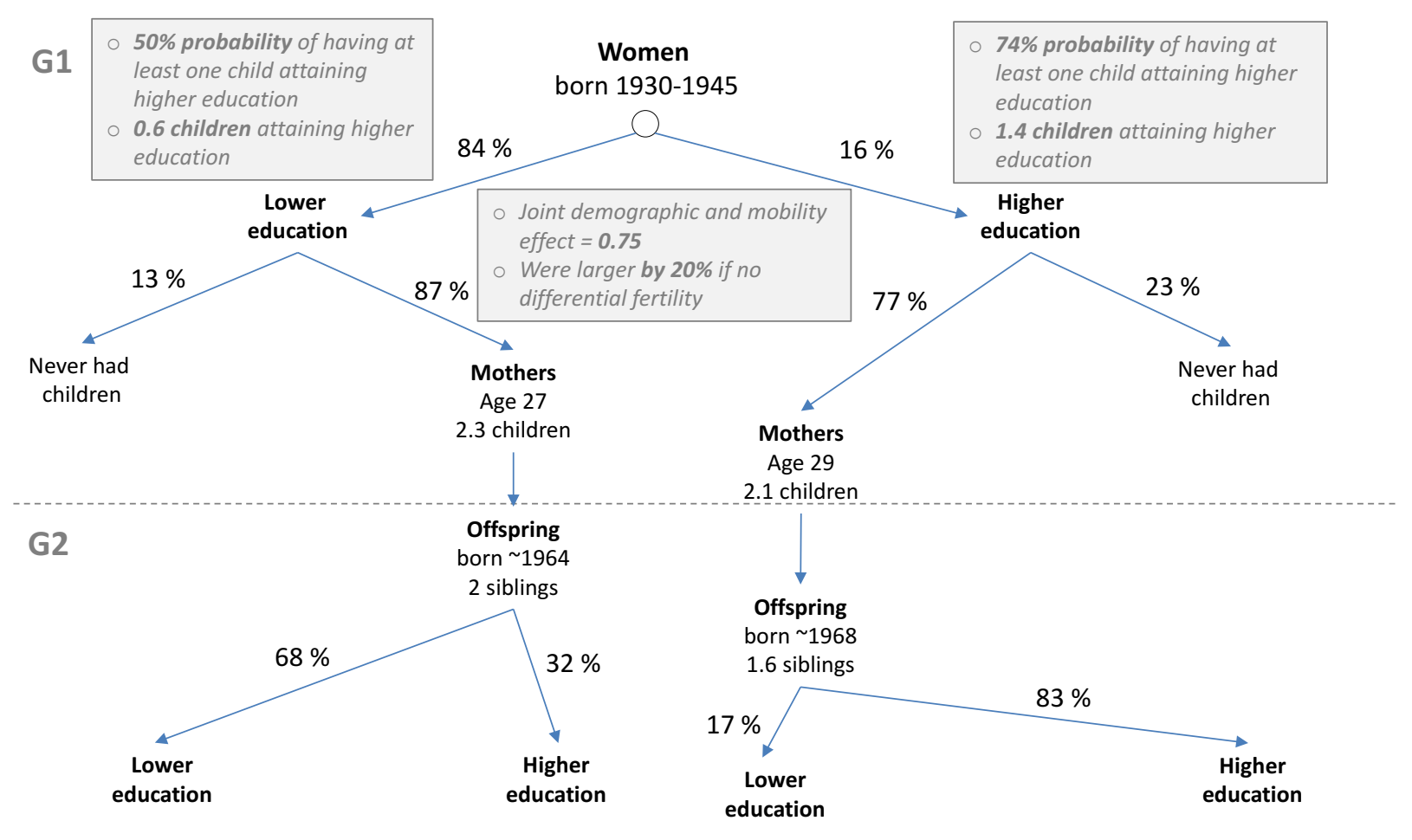

Figure 4. EdUCATIONAL REPRODUCTION OF WeSt GERMAN WOMEN

Note: Data are from NEPS and SOEP (pooled) 
Table 1. Starting Sample of Respondents

\begin{tabular}{|c|c|c|c|c|c|c|c|c|c|c|c|c|}
\hline \multirow{3}{*}{\multicolumn{2}{|c|}{ Dataset }} & \multicolumn{5}{|c|}{ Respondent } & \multicolumn{6}{|c|}{ Retrospective information on parents } \\
\hline & & \multirow[b]{2}{*}{$\begin{array}{l}\text { Birth } \\
\text { year }\end{array}$} & \multirow[b]{2}{*}{ Age } & \multirow[b]{2}{*}{$\begin{array}{c}\text { Number of } \\
\text { Siblings }\end{array}$} & \multirow[b]{2}{*}{$\begin{array}{c}\text { Higher } \\
\text { educated }\end{array}$} & \multirow[b]{2}{*}{$\begin{array}{c}\text { Born in } \\
\text { Germany }\end{array}$} & \multicolumn{3}{|c|}{ Mother } & \multicolumn{3}{|c|}{ Father } \\
\hline & & & & & & & $\begin{array}{l}\text { Birth } \\
\text { year }\end{array}$ & $\begin{array}{c}\text { Born in } \\
\text { Germany }\end{array}$ & $\begin{array}{l}\text { Higher } \\
\text { educated }\end{array}$ & $\begin{array}{l}\text { Birth } \\
\text { year }\end{array}$ & $\begin{array}{l}\text { Born in } \\
\text { Germany }\end{array}$ & $\begin{array}{l}\text { Higher } \\
\text { educated }\end{array}$ \\
\hline \multicolumn{13}{|c|}{ NEPS 2011/2012 } \\
\hline & $M$ & 1964 & 47 & 1.8 & 0.32 & 0.97 & 1937 & 0.97 & 0.10 & 1934 & 0.96 & 0.18 \\
\hline & $S D$ & 12 & 12 & 1.6 & & & 14 & & & 14 & & \\
\hline & Min & 1944 & 23 & 0 & 0 & 0 & 1888 & 0 & 0 & 1877 & 0 & 0 \\
\hline & $\operatorname{Max}$ & 1988 & 68 & 23 & 1 & 1 & 1969 & 1 & 1 & 1968 & 1 & 1 \\
\hline \multicolumn{13}{|c|}{ SOEP 2012} \\
\hline & $M$ & 1966 & 46 & 1.9 & 0.37 & 0.99 & 1938 & 0.99 & 0.10 & 1935 & 0.98 & 0.18 \\
\hline & $S D$ & 12 & 12 & 1.6 & & & 14 & & & 14 & & \\
\hline & Min & 1944 & 24 & 0 & 0 & 0 & 1896 & 0 & 0 & 1881 & 0 & 0 \\
\hline & Max & 1988 & 68 & 18 & 1 & 1 & 1972 & 1 & 1 & 1969 & 1 & 1 \\
\hline \multicolumn{13}{|l|}{ Total } \\
\hline & $M$ & 1965 & 48 & 1.8 & 0.35 & 0.98 & 1938 & 0.98 & 0.10 & 1935 & 0.97 & 0.18 \\
\hline & $S D$ & 12 & 12 & 1.6 & & & 14 & & & 14 & & \\
\hline & Min & 1944 & 24 & 0 & 0 & 0 & 1888 & 0 & 0 & 1877 & 0 & 0 \\
\hline & Max & 1988 & 70 & 23 & 1 & 1 & 1972 & 1 & 1 & 1969 & 1 & 1 \\
\hline
\end{tabular}

Note: Higher education = upper secondary degree (Abitur). $N=28,526$. Weighted by cross-sectional weights. 
Table 2. Childlessness by gender, part of Germany, education, and cohort

\begin{tabular}{lcccc}
\hline \multirow{2}{*}{ Cohort } & \multicolumn{2}{c}{ East Germany } & \multicolumn{2}{c}{ West Germany } \\
Men & Lower educated & Higher educated & Lower educated & Higher educated \\
\cline { 2 - 5 } $1930-35$ & 11.8 & 7.2 & 13.7 & 13.6 \\
$1936-40$ & 12.6 & 7.7 & 15.4 & 15.3 \\
$1941-45$ & 12.7 & 7.8 & 20.4 & 20.3 \\
Women & 12.7 & & & 23.8 \\
$1930-35$ & 8.5 & 19.0 & 13.9 & 21.3 \\
$1936-40$ & 8.3 & 13.0 & 12.3 & 23.5 \\
$1941-45$ & 12.7 & 13.7 & \\
\hline
\end{tabular}

Note: Data are from pooled external fertility data (see Table A1). Predicted probabilities based on a logit model on pooled data. Weighted by normalized survey weights. Adjusted for survey (fixed at mean) and age effects (fixed at 50+). See equation A1 in the Appendix for detailed model specification. Lower educated = less than upper secondary degree (Abitur), higher educated = upper secondary degree (Abitur). 
Table 3. Descriptive Statistics from the Perspective of G2, G1, and C1

\begin{tabular}{|c|c|c|c|}
\hline & East Germany & West Germany & Total \\
\hline \multicolumn{4}{|c|}{$\begin{array}{l}\text { A - Perspective of } G 2: \text { Offspring's parent characteristics }{ }^{\text {a }} \\
\text { Fathers' offspring }\end{array}$} \\
\hline Higher educated & 0.23 & 0.15 & 0.17 \\
\hline Year of birth & 1937 & 1937 & 1937 \\
\hline Family size & 2.8 & 2.8 & 2.8 \\
\hline \multicolumn{4}{|l|}{ Mothers' offspring } \\
\hline Higher schooling & 0.13 & 0.06 & 0.08 \\
\hline Year of birth & 1937 & 1937 & 1937 \\
\hline Family size & 2.9 & 2.9 & 2.9 \\
\hline \multicolumn{4}{|c|}{ B - Perspective of G1: Parents born 1930-1945 b } \\
\hline Higher educated & 0.24 & 0.16 & 0.18 \\
\hline Year of birth & 1938 & 1937 & 1937 \\
\hline Number of children & 2.1 & 2.2 & 2.2 \\
\hline \multicolumn{4}{|l|}{ Mothers } \\
\hline Higher educated & 0.14 & 0.06 & 0.08 \\
\hline Year of birth & 1938 & 1938 & 1938 \\
\hline Number of children & 2.2 & 2.3 & 2.3 \\
\hline \multicolumn{4}{|c|}{$\begin{array}{l}\text { C - Perspective of C1: Individuals born } 1930-1945^{c} \\
\text { Men }\end{array}$} \\
\hline Higher educated & 0.24 & 0.16 & 0.18 \\
\hline Year of birth & 1938 & 1937 & 1937 \\
\hline Cohort fertility rate $^{\mathrm{d}}$ & 1.9 & 1.9 & 1.9 \\
\hline \multicolumn{4}{|l|}{ Women } \\
\hline Higher educated & 0.15 & 0.07 & 0.09 \\
\hline Year of birth & 1938 & 1938 & 1938 \\
\hline Cohort fertility rate $^{\mathrm{d}}$ & 2.0 & 2.0 & 2.0 \\
\hline
\end{tabular}

Note: Data are from NEPS and SOEP (pooled). Higher educated = upper secondary degree (Abitur). ${ }^{\mathrm{a}} \mathrm{G} 2=$ respondents whose parents were born 1930-1945; anchor sample for fathers: $N=11,132$ (2,694 East Germany, 8,438 West Germany), anchor sample for mothers: $N=11,406$ (2,676 East Germany, 8,730 West Germany). ${ }^{\text {b }}$ Offspring sample weighted by family size weights. ${ }^{c}$ Offspring sample weighted by family size weights and the inverse probability of having children as calculated from the fertility data on cohorts $1930-1945 .{ }^{\mathrm{d}}$ Calculated by multiplying the number of children with the probability of having children. 
Table 4. Educational mobility: Offspring's chances of attaining higher education by family characteristics

West Germany

$\begin{array}{cccc}\text { Offspring of } & \text { Offspring of } & \text { Offspring of } & \text { Offspring of } \\ \text { Mothers born } & \text { Fathers born } & \text { Mothers born } & \text { Fathers born } \\ 1930-1945 & 1930-1945 & 1930-1945 & 1930-1945\end{array}$

Logit coefficients ${ }^{\mathrm{a}}$

Parent higher educated (ref. lower)

2.330 *

$2.162 *$

$1.518^{*}$

$1.563^{*}$

Family size (siblings +1$)$

$-0.272 *$

$0.234 *$

$-0.285^{*}$

$-0.252 *$

0.314

$-0.821 *$

$-0.233$

$0.474^{*}$

$0.325 *$

0.324 *

(ref. lower)

Family size (siblings +1$)$
$0.496 *$

$-0.056^{*}$

8,730
$-0.056^{*}$

8,438
$-0.043 *$

$-0.047 *$

2,676

Notes: ${ }^{\text {a }}$ Logistic regression using $G 2$ offspring samples weighted by survey-specific design weights. ${ }^{\mathrm{b}}$ AME calculated by setting survey to $0.5{ }^{*} \mathrm{p}<.01$. 
Table 5 Differential fertility and educational reproduction of birth cohorts 1930-1945 in Germany

\begin{tabular}{|c|c|c|c|c|c|c|c|c|}
\hline & \multicolumn{4}{|c|}{ West Germany } & \multicolumn{4}{|c|}{ East Germany } \\
\hline & \multicolumn{2}{|c|}{ Women } & \multicolumn{2}{|c|}{ Men } & \multicolumn{2}{|c|}{ Women } & \multicolumn{2}{|c|}{ Men } \\
\hline & $\begin{array}{c}\text { Lower } \\
\text { educated }\end{array}$ & $\begin{array}{c}\text { Higher } \\
\text { educated }\end{array}$ & $\begin{array}{c}\text { Lower } \\
\text { educated }\end{array}$ & $\begin{array}{l}\text { Higher } \\
\text { educated }\end{array}$ & $\begin{array}{c}\text { Lower } \\
\text { educated }\end{array}$ & $\begin{array}{l}\text { Higher } \\
\text { educated }\end{array}$ & $\begin{array}{c}\text { Lower } \\
\text { educated }\end{array}$ & $\begin{array}{l}\text { Higher } \\
\text { educated }\end{array}$ \\
\hline \multicolumn{9}{|l|}{ Fertility } \\
\hline $\begin{array}{r}\text { Childless } \\
\operatorname{Pr}(\mathrm{f}=0)\end{array}$ & .13 & .23 & .16 & .17 & .10 & .14 & .12 & .08 \\
\hline $\begin{array}{r}\text { Children } \mathrm{f} \mid \mathrm{f} \\
>0\end{array}$ & 2.28 & 2.14 & 2.24 & 2.11 & 2.22 & 1.99 & 2.18 & 2.02 \\
\hline $\begin{array}{l}\text { Cohort } \\
\text { fertility rate }\end{array}$ & 1.98 & 1.65 & 1.88 & 1.76 & 1.99 & 1.71 & 1.91 & 1.86 \\
\hline \multicolumn{9}{|c|}{$\begin{array}{l}\text { Offspring's Educational } \\
\text { Mobility }\end{array}$} \\
\hline Average $\mathrm{P}_{\mathrm{H} \mid \mathrm{i}}$ & .32 & .83 & .30 & .79 & .20 & .56 & .18 & .53 \\
\hline Odds Ratio & \multicolumn{2}{|c|}{$10.74^{*}$} & \multicolumn{2}{|c|}{$8.89 *$} & \multicolumn{2}{|c|}{$4.87^{*}$} & \multicolumn{2}{|c|}{$5.07 *$} \\
\hline \multicolumn{9}{|l|}{$\begin{array}{l}\text { Educational } \\
\text { Reproduction }\end{array}$} \\
\hline \multicolumn{9}{|c|}{$\begin{array}{l}\text { Production of higher } \\
\text { educated offspring }\end{array}$} \\
\hline Rate: $\mathrm{r}_{\mathrm{Hi}}$ & 0.63 & 1.38 & 0.55 & 1.38 & 0.41 & 0.95 & 0.35 & 0.99 \\
\hline $\begin{array}{r}\text { Joint effect: } \\
\mathrm{r}_{\mathrm{HH}}-\mathrm{r} \mathrm{HL}\end{array}$ & \multicolumn{2}{|c|}{$0.75^{*}$} & \multicolumn{2}{|c|}{$0.83 *$} & \multicolumn{2}{|c|}{$0.55^{*}$} & \multicolumn{2}{|c|}{$0.64 *$} \\
\hline \multicolumn{9}{|l|}{ Decomposition $^{1}$} \\
\hline Mobility & \multicolumn{2}{|c|}{$0.90^{*}$} & \multicolumn{2}{|c|}{$0.86^{*}$} & \multicolumn{2}{|c|}{$0.61 *$} & \multicolumn{2}{|c|}{$0.62 *$} \\
\hline$\%$ Fertility & \multicolumn{2}{|l|}{-20} & \multicolumn{2}{|l|}{$(-4)$} & \multicolumn{2}{|l|}{-12} & \multicolumn{2}{|l|}{ (3) } \\
\hline \multicolumn{9}{|c|}{$\begin{array}{l}\text { Production of lower } \\
\text { educated offspring }\end{array}$} \\
\hline $\begin{array}{r}\text { Joint effect: } \\
\mathrm{r}_{\mathrm{LH}}-\mathrm{rLL} \\
\text { Decomposition }^{1}\end{array}$ & \multicolumn{2}{|c|}{$-1.07^{*}$} & \multicolumn{2}{|c|}{$-0.95^{*}$} & -0.8 & & -0.6 & \\
\hline Fertility & -0.1 & & -0.09 & & -0.2 & & -0.0 & \\
\hline Mobility & -0.9 & & -0.86 & & -0 & & -0.6 & \\
\hline$\%$ Fertility & 16 & & 9 & & 26 & & (10) & \\
\hline
\end{tabular}

Note: Data are from NEPS and SOEP (pooled). Lower educated = less than upper secondary degree (Abitur), higher educated $=$ upper secondary degree (Abitur). ${ }^{1}$ Fertility (indirect effect) is the part of the joint effect that is due to differential fertility; mobility (direct effect) is the part of the joint effect that is due to differences in children's origin-specific chances. All calculations based on survey weights. Additional weights adjusting for retrospective sampling bias and survey effects. Standard errors in statistical tests calculated via Jackknife. ${ }^{*} \mathrm{p}<.01$. 
Table 6. Population Renewal Models - Counterfactual outcomes for G2

\begin{tabular}{|c|c|c|c|c|c|c|c|c|c|c|c|c|}
\hline \multirow{4}{*}{ Offspring $(G 2)$ of $G 1$} & \multicolumn{6}{|c|}{ West Germany } & \multicolumn{6}{|c|}{ East Germany } \\
\hline & \multicolumn{3}{|c|}{ Women } & \multicolumn{3}{|c|}{ Men } & \multicolumn{3}{|c|}{ Women } & \multicolumn{3}{|c|}{ Men } \\
\hline & $\begin{array}{c}\% \\
G 2 / G 1\end{array}$ & $\begin{array}{l}\% \\
\mathrm{H}\end{array}$ & $\begin{array}{l}\text { Odds } \\
\text { Ratio }\end{array}$ & $\begin{array}{c}\% \\
G 2 / G 1\end{array}$ & $\begin{array}{l}\% \\
\mathrm{H}\end{array}$ & $\begin{array}{l}\text { Odds } \\
\text { Ratio }\end{array}$ & $\begin{array}{c}\% \\
G 2 / G 1\end{array}$ & $\begin{array}{l}\% \\
\mathrm{H}\end{array}$ & $\begin{array}{l}\text { Odds } \\
\text { Ratio }\end{array}$ & $\begin{array}{c}\% \\
G 2 / G 1\end{array}$ & $\begin{array}{l}\% \\
\mathrm{H}\end{array}$ & $\begin{array}{l}\text { Odds } \\
\text { Ratio }\end{array}$ \\
\hline & 195 & 34.9 & 10.74 & 185 & 37.0 & 8.89 & 196 & 24.9 & 4.87 & 190 & 26.4 & 5.07 \\
\hline \multicolumn{13}{|l|}{ Counterfactual scenarios (G1) } \\
\hline $\begin{array}{l}\text { (1) If } \mathrm{H} \text { had } \\
\text { fertility of } \mathrm{L}\end{array}$ & 198 & 35.2 & 9.33 & 187 & 37.2 & 7.96 & 200 & 25.1 & 4.36 & 191 & 25.9 & 4.54 \\
\hline $\begin{array}{r}(2) \text { If } L \text { had } \\
\text { fertility of } H\end{array}$ & 165 & 37.1 & 9.84 & 175 & 38.8 & 8.26 & 172 & 26.8 & 4.44 & 186 & 27.6 & 4.64 \\
\hline $\begin{array}{r}\text { (3) If H's children had L's mobility } \\
\text { parameter }\end{array}$ & 195 & 31.8 & 1.09 & 185 & 29.8 & 1.08 & 196 & 20.6 & 1.10 & 190 & 18.6 & 1.09 \\
\hline $\begin{array}{r}\text { (4) If L's children had H's mobility } \\
\text { parameter }\end{array}$ & 195 & 81.4 & 1.15 & 185 & 77.2 & 1.12 & 196 & 53.1 & 1.12 & 190 & 51.1 & 1.12 \\
\hline
\end{tabular}

Note: Data are from NEPS and SOEP (pooled). L = less than upper secondary degree (Abitur), $\mathrm{H}=$ upper secondary degree (Abitur). Logic of counterfactual analysis: (1) + (2) exchanging fertility distributions of lower and higher educated $G 1$ individuals, (3) + (4) exchanging children's probability of obtaining higher education (conditional on number of siblings) among lower and higher educated $G 1$ parents. Intergenerational outcomes: \% $G 2 / G 1=$ rate of demographic reproduction, $\% \mathrm{H}=$ percentage of $G 2$ offspring with higher education. Odds ratio $=$ factor difference in odds of attaining higher education between children from parents with lower and higher education. 


\section{ONLINE APPENDIX}
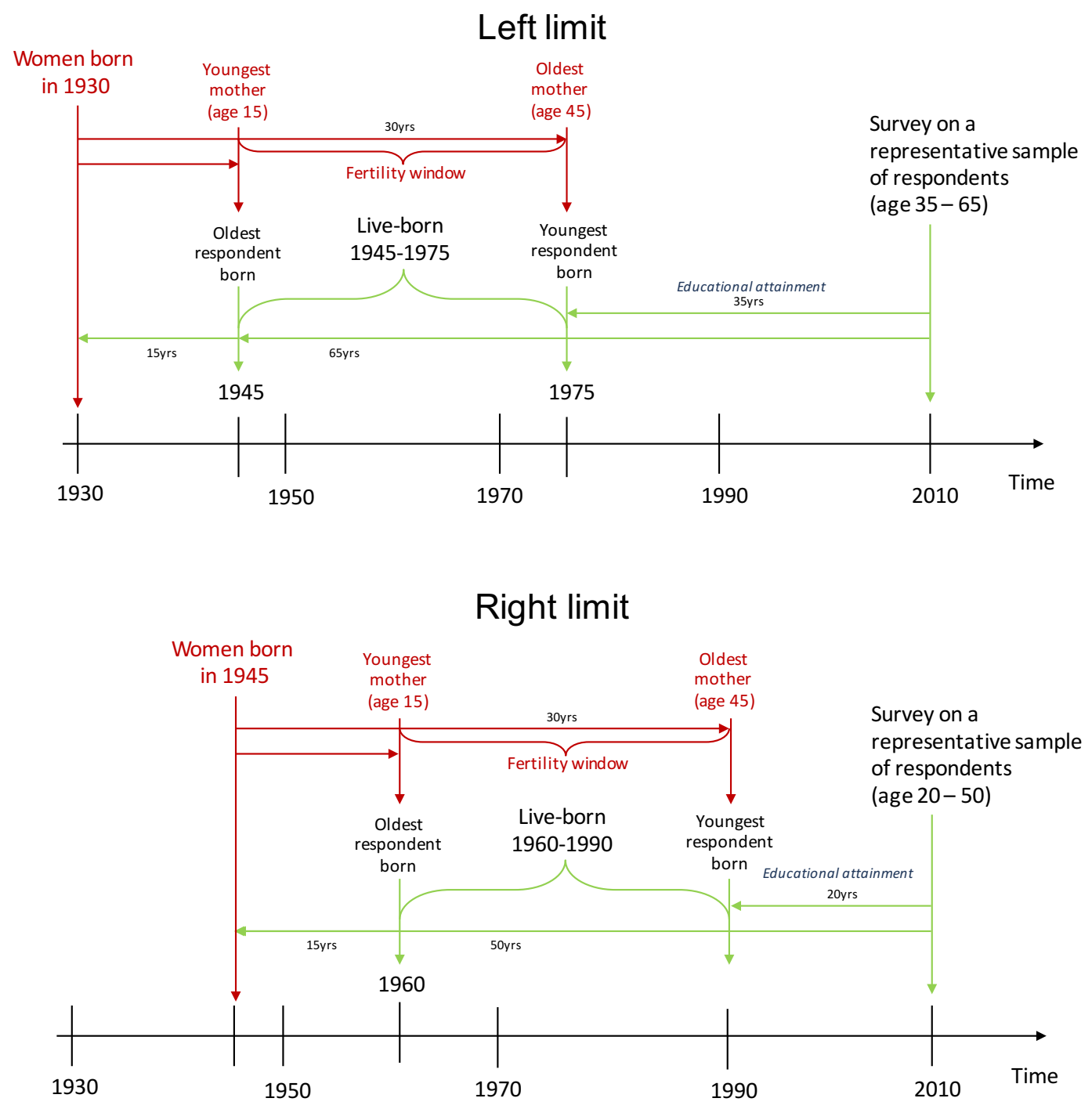

FiguRE A1. RATIONALE OF SELECTING A COHORT OF G1 PARENTS 
Number of live born in Germany

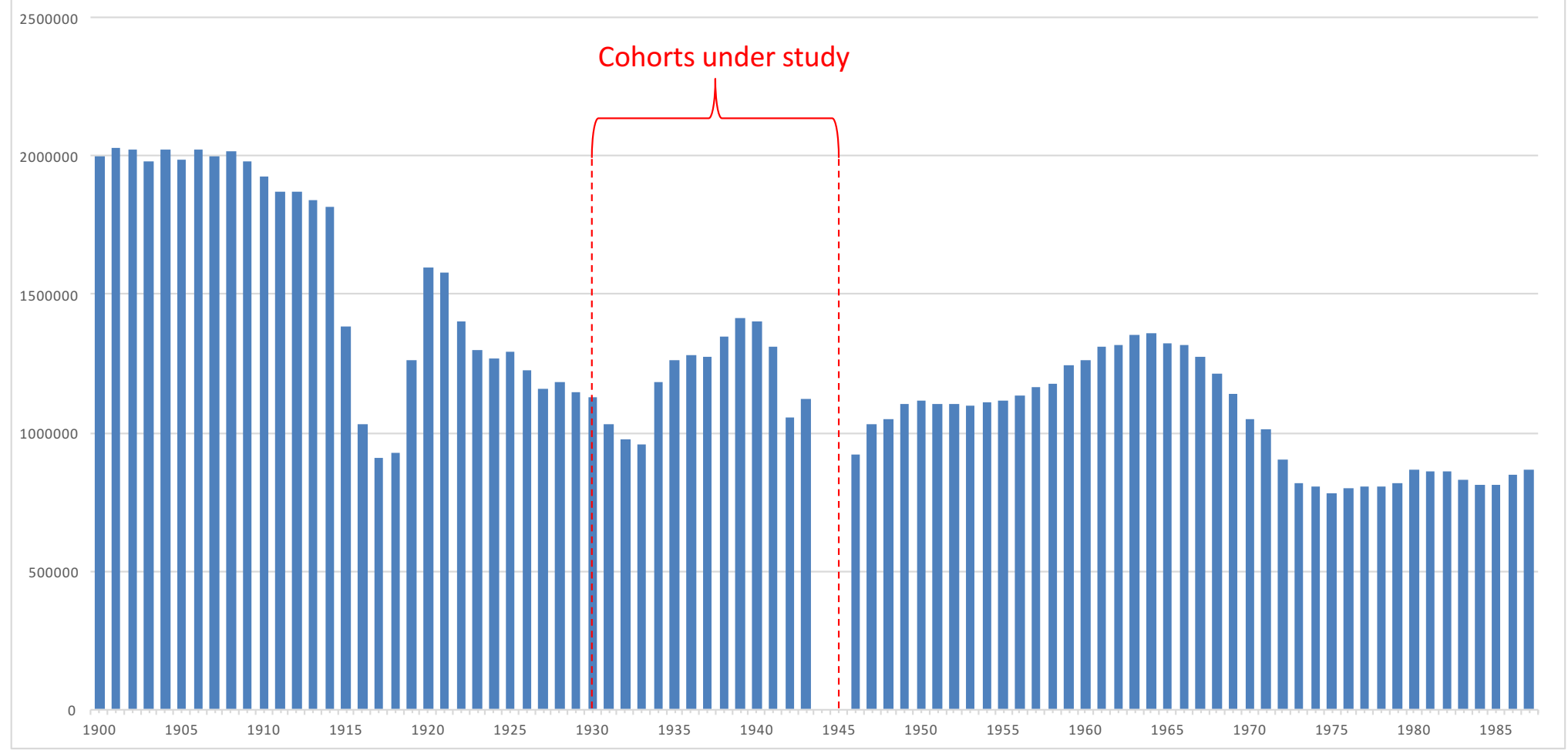

FIGURE A2 TARGET COHORTS 1930-1945 LOCATED IN HISTORICAL POPULATION DATA ON COHORT SIZES IN GERMANY. Note: Data are from Sensch (2004). 
Table A1. Overview of Pooled Fertility Data

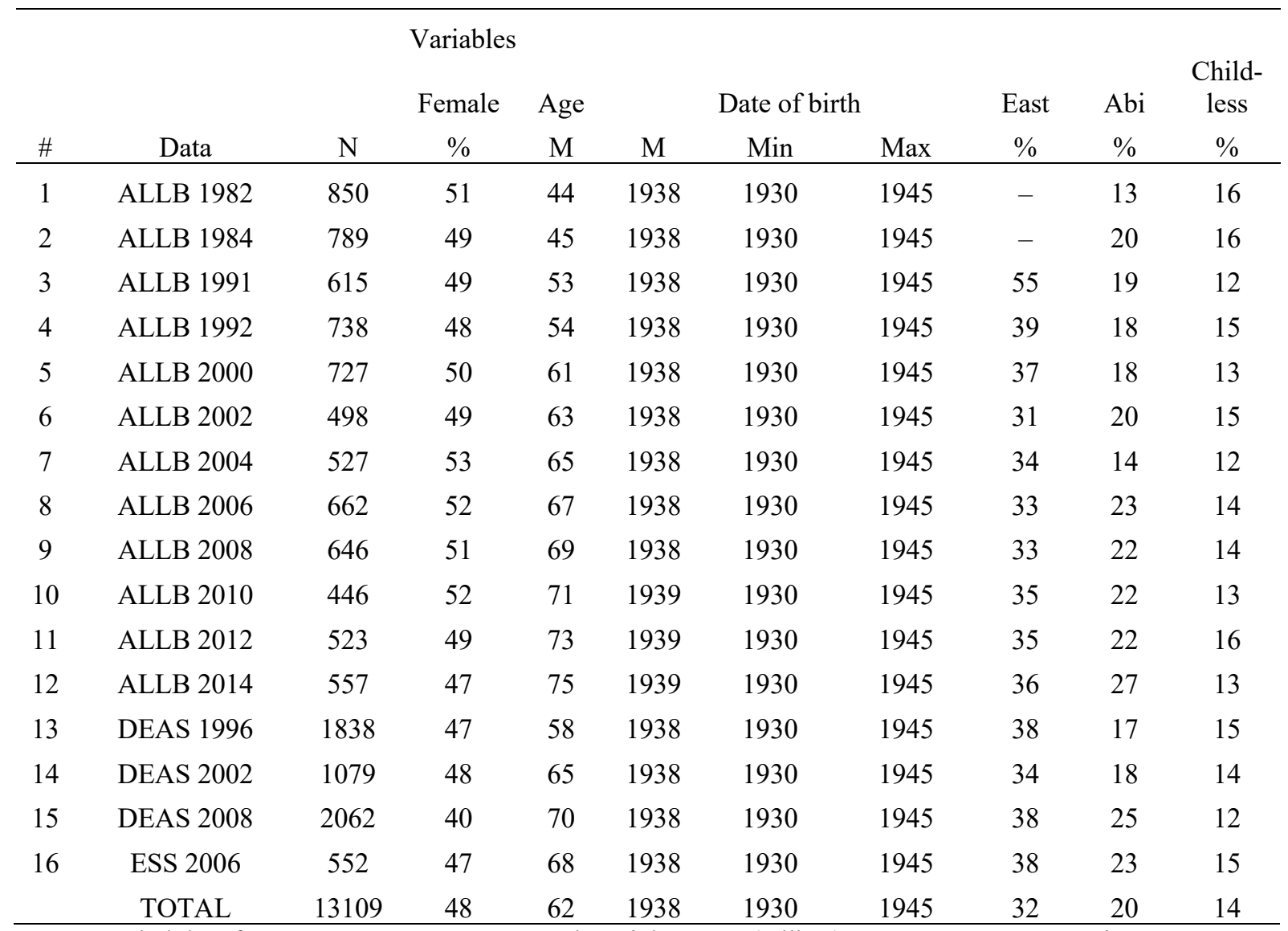

Notes: Pooled data from ALLB = German General Social Survey (Allbus), DEAS = German Ageing Survey, ESS = European Social Survey (German subsample). Only West Germany covered in Allbus 1982 and 1984. $\mathrm{Abi}=$ upper secondary degree or higher. Sample data, unweighted. 
Table A2. Decomposition: Observed and Hypothetical Rates of Producing Offspring in Educational Categories

\begin{tabular}{|c|c|c|c|c|}
\hline \multicolumn{5}{|c|}{ Women / Men } \\
\hline & \multicolumn{2}{|c|}{ \# children with L } & \multicolumn{2}{|c|}{ \# children with $\mathrm{H}$} \\
\hline Offspring's & \multicolumn{2}{|c|}{ Fertility pattern } & \multicolumn{2}{|c|}{ Fertility pattern } \\
\hline behaviour & $\mathrm{L}$ & $\mathrm{H}$ & $\mathrm{L}$ & $\mathrm{H}$ \\
\hline \multicolumn{5}{|c|}{ West Germany } \\
\hline $\mathrm{L}$ & $1.35 / 1.32$ & $1.09 / 1.21$ & $0.63 / 0.55$ & $0.56 / 0.55$ \\
\hline $\mathrm{H}$ & $0.37 / 0.43$ & $0.28 / 0.37$ & $1.61 / 1.44$ & $1.38 / 1.38$ \\
\hline \multicolumn{5}{|c|}{ East Germany } \\
\hline $\mathrm{L}$ & $1.59 / 1.56$ & $1.34 / 1.50$ & $0.41 / 0.35$ & $0.38 / 0.37$ \\
\hline $\mathrm{H}$ & $0.94 / 0.95$ & $0.76 / 0.87$ & $1.05 / 0.97$ & $0.95 / 0.99$ \\
\hline
\end{tabular}

Notes: $\mathrm{L}=$ less than upper secondary degree (Abitur), $\mathrm{H}=$ upper secondary degree (Abitur). 
Table A3. Probability of Having At Least One Child With Higher Education.

\begin{tabular}{|c|c|c|c|c|c|c|c|c|}
\hline Territory & \multicolumn{4}{|c|}{ West Germany } & \multicolumn{4}{|c|}{ East Germany } \\
\hline Gender & \multicolumn{2}{|c|}{ Women } & \multicolumn{2}{|c|}{ Men } & \multicolumn{2}{|c|}{ Women } & \multicolumn{2}{|c|}{ Men } \\
\hline Cases & \multicolumn{2}{|c|}{$\mathrm{N}=8,730$} & \multicolumn{2}{|c|}{$\mathrm{N}=8,438$} & \multicolumn{2}{|c|}{$\mathrm{N}=2,676$} & \multicolumn{2}{|c|}{$\mathrm{N}=2,694$} \\
\hline Schooling $(i)$ & $\mathrm{L}$ & $\mathrm{H}$ & $\mathrm{L}$ & $\mathrm{H}$ & $\mathrm{L}$ & $\mathrm{H}$ & $\mathrm{L}$ & $\mathrm{H}$ \\
\hline$P\left(C^{H}>0\right)$ & .50 & .74 & .45 & .79 & .36 & .67 & .31 & .71 \\
\hline Total effect (OR) & \multicolumn{2}{|c|}{$2.9^{*}$} & \multicolumn{2}{|c|}{$4.4^{*}$} & \multicolumn{2}{|c|}{$3.7^{*}$} & \multicolumn{2}{|c|}{$5.4^{*}$} \\
\hline
\end{tabular}

Note: Data are from NEPS and SOEP (pooled). Probabilities estimated based on Equation A2. Lower educated = less than upper secondary degree (Abitur), higher educated = upper secondary degree (Abitur). All calculations based on survey weights. Additional weights adjusting for retrospective sampling bias and survey effects.

Standard errors in statistical tests calculated via Jackknife. ${ }^{*} \mathrm{p}<.01$. 
Equation A1. Logit model for predicting levels of childlessness

We used the following logit specification for estimating levels of childlessness based on pooled fertility data:

$$
\begin{aligned}
\operatorname{Logit}(\operatorname{Pr}(f= & 0 \mid X)) \\
& =a+b_{1} C_{36-40}+b_{2} C_{41-45}+b_{3} E_{H}+b_{4} G_{\text {female }} \\
& +b_{5} P_{\text {West }}+b_{6} C_{1} P_{\text {West }}+b_{7} C_{2} P_{\text {West }}+b_{8} E_{H} P_{\text {West }} \\
& +b_{9} C_{1} G_{\text {female }}+b_{10} C_{2} G_{\text {female }}+b_{11} E_{H} G_{\text {female }} \\
& +b_{12} P_{\text {West }} G_{\text {female }}+b_{13} C_{1} P_{\text {West }} G_{\text {female }} \\
& +b_{14} C_{2} P_{\text {West }} G_{\text {female }}+b_{15} E_{H} P_{\text {West }} G_{\text {female }}+\text { Age } \\
& + \text { Age } e_{\leq 40}+\boldsymbol{I}_{\text {data }} \boldsymbol{i}
\end{aligned}
$$

with dummies for birth cohorts (C), a dummy for high versus low education (E), a dummy for female versus male $(G)$, a dummy for part of Germany - West versus East - (P), dummies for age at survey (Age), and a vector of dummy variables controlling for survey effects (I). 


\section{Equation A2. Estimating prospective probabilities}

Probability metrics have been used in recent studies on educational reproduction (Lawrence and Breen 2016). With complete prospective data (on individuals and all their children) this probability can be estimated in a straightforward way. Although our method draws on information about only one child (i.e., the respondent) per parent, we can approximate this probability using the weights introduced above. The average probability of having at least one higher-educated child is equal to the inverse probability of having no higher-educated child weighted by the probability of having any children at all:

$$
E\left[\operatorname{Pr}\left(C^{i j} \geq 1\right)\right]=(1-\operatorname{Pr}[f=0 \mid i]) \cdot E\left[1-\left(1-p_{i j \mid f}\right)^{f}\right]
$$

where $C^{i j}$ is a child with educational level $i$ born to an individual of educational level $j$, $\operatorname{Pr}\left[f_{j}=0\right]$ is the probability to remain childless for an individual with educational level $j, p_{i j \mid f}$ is the probability that a child has educational level $i$ given a parent with education $j$ (originspecific chances), and $f$ is family size. The expectation in the product term on the right-hand side is an estimate for the average probability of an individual with education $j$ to have at least one child attaining educational level $i$. It can be calculated by predicting $p_{i j \mid f}$ for each case and calculating the mean of $1-\left(1-p_{i j \mid f}\right)^{f}$ using family weights (equation 19). 